\title{
3. Learning from transformative science approaches for sustainability
}

Over the last two decades sustainability science has gained acceptance as a new research field to address the fundamental challenges raised by the interactions between increasingly interconnected human and natural systems (Yarime et al., 2012; Van der Leeuw et al., 2012). Since its inception, sustainability science has evolved to become a solutionoriented interdisciplinary research field inspired by successful initiatives of participatory research practices between scientific and extra-scientific expertise. More recently, sustainability science emerged at the centre of a broad set of research and innovation activities relevant to society's effort to support an effective transition towards strong sustainability (Clark and Dickson, 2003).

However, sustainability science today faces important challenges in its attempt to overcome the inertia of existing disciplinary and valueneutral research frameworks. First, in spite of growing evidence of the need to develop major transformative research efforts for sustainability, many research efforts for sustainability are still based on monodisciplinary thinking, equilibrium analysis and simplified mathematical models applied to complex problems. Second, scholars are faced with a lack of attention in sustainability research to pressing new issues that were initially considered at the margin of their concerns, but which now appear to put a damper on many sustainability efforts, such as the global financial crisis and socio-ecological catastrophes generated by the widespread use of high-risk technologies. The 2008 financial crisis had a major impact on the decline in policy support for sustainable development, in particular through the slowdown of the funding of major environmental policy programmes as a consequence of the budgetary discipline imposed on states. The impact of the use of high-risk technologies can be witnessed by a series of well-documented ecological catastrophes, amongst which the nuclear accident at Fukushima is a tragic example. This tragedy not only had important ecological consequences, revealed inter alia by alarming studies on genetic mutations in butterflies as a consequence of exposure to radiation (Hiyama et al., 2012), but has also led to major socio-economic consequences for the population of Japan. 
Much can be learned from existing efforts by scholars and practitioners to build a viable alternative way of organizing research on sustainability, which goes beyond the shortcomings of conventional disciplinary scientific research practices. To this end, this chapter will examine a set of transdisciplinary and interdisciplinary research programmes in the field of economics and environmental sciences, which have made major contributions to sustainability science, and it will highlight some of the challenges they face in overcoming disciplinary inertia. This chapter both examines key areas of research that have been prominent amongst sustainability scholars since the Brundtland report, that is natural resource management and the rethinking of economic growth, and more recent attempts by scholars and practitioners for integrating the issues of financial globalization and governance of technological development into the strong-sustainability research agenda. More specifically, the following sections will examine major transformative science approaches in:

a. ecological economics for natural resources and ecosystems management (section 3.1);

b. Earth System Science for ecosystems management on the global scale (section 3.1);

c. integrated and multi-criteria* assessments as an alternative to GDP as a measure of economic development (Gross Domestic Product) accounting (section 3.2);

d. post-Keynesian macroeconomics as an alternative to the neoclassical modelling of financial markets (section 3.2);

e. transition approaches to the transformation of socio-technological systems (section 3.3);

f. Veblean evolutionary economics approach to long-term innovation processes (section 3.3).

Section 3.4 concludes and draws conclusions for the organization of the research process in sustainability science.

\subsection{RETHINKING NATURAL RESOURCES AND ECOSYSTEMS MANAGEMENT IN INTEGRATED ECOLOGICAL AND ECONOMIC SYSTEMS}

There is an emerging consensus in the field of natural resources and ecosystems management regarding the need to adopt a complex systems perspective on natural resources and ecosystems management, as shown for example through a survey of senior scientists of the American Association 
for the Advancement of Science (Berkes et al., 2003a, pp. 1-2). First, according to the scientists who took part in the survey, the analysis of natural resource and environmental problems needs to take into account the complexity of the interactions between natural and social systems, in addition to the recognition that natural and social systems are complex systems in themselves (Norgaard, 1994; Berkes and Folke, 1998). Second, there is a consensus amongst these scientists on the need for broader public participation. Scientific research needs to be undertaken with greater attention to its social context, and the interaction between science and society is increasingly seen as important (Jasanoff et al., 1997). The kind of research that is needed may be "created through processes of co-production in which scholars and stakeholders interact to define important questions, relevant evidence, and convincing forms of argument" (Kates et al., 2001).

To summarize, sustainability scientists recognize that the management of global and regional resources is not an ecological problem, nor an economic one, nor a social one alone. Sustainable management of these resources is a combination of all three. And yet, much scientific research practice is still far removed from adopting an integrated perspective across these three dimensions (Holling, 2003, p. xviii). For example, sustainable designs by ecologists driven by conservation interests often ignore the need for an adaptive form of economic development that emphasizes individual enterprise and flexibility. Economists who are driven by an industrial and technological development perspective often act as if the uncertainty of nature can be replaced by human engineering and incentive based controls, or ignored altogether. Finally, those driven by social interests often act as if community development and empowerment can surmount any constraints of nature or of external forces. As a result, as highlighted by Holling (2003, p. xix):

as investments fail, the policies of government, private foundations, international agencies and non-governmental organisations (NGOs) swing from emphasising one kind of partial solution to another. Over the last decades, such policies have oscillated from large investment schemes, to narrow conservation ones, to equally narrow community development ones, to libertarian market solutions. There has been lots of despair over failures but little benefit from the learning that has occurred.

\subsubsection{The Pathology of the Conventional Mono-disciplinary Approaches to Natural Resources and Ecosystems Management}

Paradoxically, the ability of scientists and policy makers to provide solutions to the extinction and depletion crisis has not followed a parallel path to the development of sophisticated analytical tools and technologies, 
available to increase our understanding and capacity for action in an integrated and participatory way. In the area of resource and environmental management more specifically, there was a great deal of faith in our growing scientific understanding of ecosystems in ecology and in the application of sophisticated market mechanisms to problems such as air pollution and fishery management through individually allocated and transferable quotas (as reflected, for example, in the perspectives that were at the heart of the Rio Convention in 1992). However, ever since, in spite of major efforts and progress in some areas, a gap has been developing between the worsening of the global environmental problems and our lagging ability to solve them in practice.

In spite of these flaws, dominant perspectives in ecology, economy and social participation studies still adopt simple mathematical or theoretical models in disciplinary approaches, leading to widespread ineffective management strategies. For example, in the field of ecology, both scientists and policy makers still massively rely on the ecological concept of maximum sustainable yield*, in spite of the available evidence of the shortcomings of this concept (Berkes et al., 2003a, p. 7). Indeed, for much of ecology and resource management science, complexity is still a subversive idea that challenges the basis of population and yield models. However, as early as 1977, Larkin (1977) pointed out in a seminal paper that the maximum sustainable yield concept assumes away such complexity as food-web relations and focuses on single species yield, in isolation from other dynamics. Another study, by Lugo (1995), pointed out that trying to quantify supposedly sustainable levels of yield in tropical forests rarely leads to ecosystem sustainability. If the objective is conservation, a strategy focusing on the resilience - the ability of a complex system to regenerate or resist in the presence of external shocks - of ecological processes such as plant succession, may be the most effective way to promote tropical forest sustainability. Therefore a combination of qualitative analysis of key processes contributing to adaptability and resistance to external shocks and quantitative analysis of the interaction amongst a small set of structuring variables (Gunderson, 2003, p. 40) seems a more useful approach for informing management decisions than simplified models of single sustainable yield variables only.

Similar simplified modelling and disciplinary thinking prevails in many of the economic approaches towards sustainability. Indeed, the prevailing thinking, even in the models that integrate both economic and biophysical variables in the scientific exercise, is still one of equilibrium or partial equilibrium analysis - based on Walrasian general equilibrium systems - which can only predict smooth, reversible behaviours (Patterson and Glavovic, 2013). The systematic evacuation in these models of non-equilibrium 
phenomena, such as systems crises, thresholds leading to system collapse or unpredictable dynamics, is clearly ignoring the evidence of the many sudden system collapses or qualitative shifts in coupled socio-ecological systems that have been documented in the literature, such as the sudden collapse of the cod fisheries in Northern Canada in the 1980s (Stern, 2011). In a broader context, the marginalization of system risks and uncertainties in academic economics and by policy makers has now been recognized as one of the important causes of the current financial crisis (as will be discussed below in section 3.2.3 (Colander et al., 2009)). Rather than sticking to equilibrium models that seem ill-suited to deal with strong sustainability problems, a more promising road seems to be to recognize the complex system features and learn from other disciplines (such as policy and planning sciences) with a longer history of dealing with issues of risk and uncertainty. This would not lead to the abandonment of economically-oriented methods: rather, complex systems thinking leads to a better integration between these methods and methods from other disciplines, and enriches them by embracing concepts such as adaptive management (Holling, 2001) or multi-criteria assessment (cf. section 3.2.2).

Finally, even in approaches that favour co-production of knowledge between scientists and social actors/practitioners, the interaction of scientists and social actors is often based on simplified modelling tools which are used and presented as a basis for the discussion. Such a reliance on simple equilibrium models prevents a broader debate occurring, for instance on the role of uncertainty and the ways to organize adaptive, iterative learning processes.

For example, in a well-studied case of the environmental assessment of the sudden die-off of sea grass in the Everglades in Florida Bay (South California, US), in the 1980 s, a set of seven simple isolated variables were proposed to the stakeholders and contrasted as possible hypotheses for explaining the die-off (Gunderson, 2003, p. 40). In this model, policy makers presented the problem as a smooth trade-off between the ever dryer Everglades due to the draining of the Kissimmee River for agriculture and grazing land on the one hand, and negative species response to the pumping of fresh water in the ecosystem to for restoration on the other hand. According to the model, the fresh water resulted in the dieoff of the sea grass and the decline in wading-bird species that depend on the sea grass ecosystem. However, the tinkering with water regulations in the Everglades that resulted from this simplified analysis has led to compromise options with lose-lose outcomes for all interests involved. Policy makers focused their action on one supposed cause (lack of fresh water) of the crisis which was, in reality, caused by a combination of several interacting human and environmental factors, such as water use by agricultural 
practices and tourism, and unsustainable environmental policies in the nearby urban areas, to the point where extra water was delivered to the bay, with the counterproductive result of hydrologic restoration being delayed rather than accelerated (Walters, 1997). It is only through shifting to a different approach in the 1990s, which adopted complex and integrated socio-ecological frameworks, that the full impacts of the environmental degradation on the quality of life in the entire sub-region became apparent and that a more integrated approach, in concert with the key stakeholders, was adopted.

The failures to build integrated approaches in ecology, economics and social sciences for natural resources management have led to what Holling has called "the regional resource and development pathology" (Holling and Meffe, 1996), the main features of which are the rapid reduction of diversity and spatial variability of ecosystems. Typically, even if in an initial phase new policies succeeded in reversing some of the negative trends, subsequent implementation action based on narrow and rigid action fails to remain open to systemic interdependencies, uncertainties and the need for iterative, adaptive management. The result, in rich regions, is short periods of "spasmodic lurches" of learning (Holling, 2003, p. xviii), with expensive actions directed to reversing the worst of the consequences of past mistakes later. One example is the expensive effort that is now being undertaken to restore the Everglades ecosystem - the largest restoration effort that has ever been attempted in the US. In poorer regions, the result is dislocation of people, with uncertain results for the long-term improvement of the ecosystems (Holling, 2003).

\subsubsection{Ecological Economics as a Transdisciplinary Research Effort for Integrating Complex Economic and Biophysical System Dynamics}

The empirical evidence of the natural resource management "pathology" gathered by scholars and practitioners of natural resources and ecosystems management clearly shows the need to move towards an integrated perspective on socio-economic and biophysical systems. The latter recognizes the role of the interaction amongst multiple and multi-scale processes, with a view to bridging the gap between scientific knowledge on the one hand and the ability to govern the transition towards sustainability on the other.

However, institutional resistance and disciplinary inertia lead to a slow recognition of these requirements of sustainability research in contemporary science practice. The slow recognition of the need to adopt an integrated perspective on the complex economic and biophysical system dynamics in sustainability research is especially strong in the field of economics. This is partially related to the belief in a physics-like positivistic 
epistemology by large parts of the scholars of the discipline (Spash, 2012), but is also due to the political climate of neo-liberal deregulation and unilateral pro-market globalization that prevailed in much environmental policy during the last two decades of the twentieth century.

After a set of conceptual and methodological innovations that followed the publication of ground-breaking works in the 1970s, such as the Limits to Growth report by a team of scholars at the Massachusetts Institute of Technology (Meadows et al., 1972) and Herman Daly's work on the steadystate economy (Daly, 1977), the entire thrust of the work on sustainability in economics seemed to have been narrowed down by the mainstream monodisciplinary and neoclassical thinking during the 1980s (Holt and Spash, 2009). Mainstream economists simply asserted that, with its optimization models and welfare theory, neoclassical economics is able to produce theoretical explanations of how environmental problems can be evaluated and solved. They argued that most environmental problems are anomalies correctable by taxes or tradable permit markets (Holt and Spash, 2009, p. 6). According to these economists, there is no need to go beyond a worldview of rational utility-maximizing agents and profit-maximizing firms. Resources are considered generally substitutable and, where they might run out, price changes are expected to stimulate new backstop technologies and resources.

Frustration with this outlook and methodology was growing. As a response, in 1987, ecological economists established their own journal for transdisciplinary research (Ecological Economics) and created the International Society for Ecological Economics a year later. The main difference between ecological economics and the mainstream is the interdisciplinary focus of ecological economics and its pluralistic methodological approach, combining field research, qualitative, comparative case studies, statistical analysis and mathematical modelling, amongst others. This is in clear contrast with mainstream economics which, as articulated by Norgaard, is "dominated by one pattern of thinking and one standard of proof, respectively the market model and econometrics" and where "field knowledge and observation per se are little valued" (1989, p. 37). For example, in the early discussions on sustainability, leading mainstream environmental economists such as Dasgupta and Heal (1974) and Solow (1974) claimed that there were no fundamental scarcity problems. Scarcity was only relative as there was always the opportunity of substitution. The key point is that this argument was not based on empirical observation, but followed directly from the usual modelling assumptions of the neoclassical economic framework (Vatn, 2009, p. 123; see also the discussion in section 1.1).

Taking issue with conventional economics that often downplays the role of the environment, and conventional ecology that downplays socioeconomic factors, ecological economics tries to bridge the two disciplines to 
promote an integrated view of economics within the ecosystem (Costanza, 1991). Among the defining characteristics of ecological economics are: the view of the economic system as a subset of the ecological system; a primary interest in natural capital; a greater concern with a wider range of values; and longer time horizons than those normally considered by economists (Berkes et al., 2003a, p. 11). Ecological economics emphasizes irreversibility, hence real or historic time, and path-dependency (Vatn, 2009 , p. 123). This has brought ecological economics to adapt concepts from complex systems theory, emphasizing the multi-scale attributes of socio-ecological systems and the features of ignorance and radical uncertainty that are fundamental to the knowledge of these systems.

Within this set of common assumptions, some researchers in ecological economics have adopted methodologies that are closer to conventional environmental economics, while others have developed more innovative interdisciplinary and transdisciplinary approaches (see, for example, the debate on methodology in Spash, 2012; Baumgaertner and Quaas, 2010; van den Bergh, 2010; Illge and Schwarze, 2009). As with the other approaches analysed in this book, the contribution of these various attempts to sustainability science will depend on their ability to combine an interdisciplinary approach with the development of an ethical framework for strong sustainability and a transdisciplinary organization of the research process.

The interdisciplinary approach to ecological economics requires the understanding of the key concepts and language of other disciplines, but also changes in knowledge in the disciplinary fields as a result of the interaction between the different subject areas. On the one hand, the role of the environmental sciences in ecological economics changes in the light of the social sciences, by recognizing irreducible uncertainty and the systemic interconnection of various components of the systems. On the other hand, the key role of the distribution of rights to land and natural resources has been reconsidered in the economic analysis. Indeed ecological economics recognizes the fact that past moral choices with respect to the distribution of rights to land and natural resources are not value-neutral and also affect the calculation of values expressed in markets today, and the access to capital, land and education that affect income (Norgaard, 2009, p. 84). Moreover, value systems beyond the optimal satisfaction of individual needs and wants need to be tapped to consider whether we want to give future generations the same rights as we enjoy today. The focus on nonutilitarian values leads in turn to criticism of commensurability of values and an adoption of lexicographic* preferences, which cannot be ranked on an ordered preference scale, as in conventional neoclassical economics (Spash, 1998; 2000). In short, the transdisciplinary research programme of 
ecological economics integrates the idea that sustainability is also a matter of rights and ethics, and is not confined to economic and ecological considerations alone.

\subsubsection{Global Science Partnerships to Address Global Environmental Change}

\section{The Millennium Ecosystems Assessment}

Sustainability scientists have used ecological economics to develop major new concepts and approaches for dealing with natural resources and ecosystems' management. Some of these have found an ever broader acceptance by policy makers and practitioners, such as the concepts of ecological footprint, multi-criteria analysis based on incommensurable lexicographic preferences and adaptive co-management of ecosystems. A prominent example which illustrates the growing influence of the concepts developed in ecological economics is the vast international assessment exercise that was undertaken under the programme of the Millennium Ecosystems Assessment.

The Millennium Ecosystems Assessment, released in 2005, is an international synthesis by over 1300 of the world's leading scientists, which analysed the state of the earth's ecosystems and provided summaries and guidelines for decision-makers in a set of five volumes. The assessment proved to be a much more open forum than the mainstream approach to natural resource and ecosystems management reviewed above. In particular, by adopting an integrated perspective (see Figure 3.1 for the conceptual model developed for the assessment), and involving a broad range of stakeholders in the process, the participants in the assessment exercise readily saw how global inequality issues and market solutions were inherently related. For instance, markets to save trees to sequester carbon are being established in poor nations where the poor are "willing" to stop using forests because the rich have the economic power to buy up the rights of the poor to stop them from using other ecosystem services of the forest (Norgaard, 2009, p. 92). As a consequence, carbon sequestration is cheaper than it would be in a world with less income disparity. The rich can continue to drive their sports utility vehicles (SUVs) because the poor are willing to forgo using their forests. Once this was made clear within the assessment exercise, it was very difficult to use prices generated in markets as neutral values. In short, the open participatory process of the Millennium Assessment began to deconstruct the dominant "cureall" market solution and propose a more integrated and open normative framework.

By adopting in addition a participatory transdisciplinary perspective on socio-ecological interactions, instead of the simplified a priori 


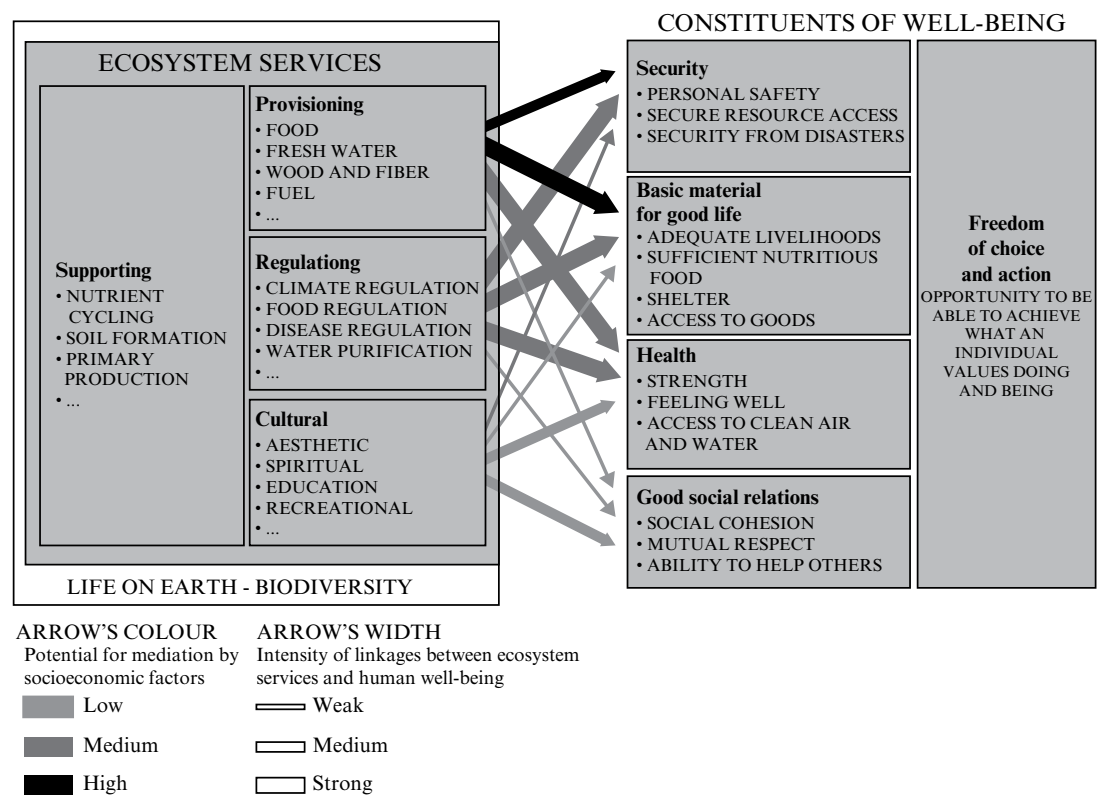

Source: MEA (2005, p.vi).

\section{Figure 3.1 Linkages between ecosystem services and human well-being}

utilitarian framing of mainstream economics, the relationship between ecosystem services and human well-being is illuminated in a richer way (Polishchuk and Rauschmayer, 2012). This is particularly clear in the case of local cultural practices that have long remained undervalued in mono-disciplinary economic analysis. For example, a case study on coastal fisheries in Sweden shows how different local communities have independently developed dynamic, self-regulating patterns in order to adapt to the naturally fluctuating fish resources and to preserve the fishery ecosystem on which they rely for their livelihood. In-depth analysis revealed patterns such as the conscious integration between landbased and fishery activities, which allowed the fishers to switch between a diverse set of occupations, and the seasonal rotation of fishing areas among the fishers in the coastal community, where the allocation is decided by drawing lots (Hammer et al., 1993).

In other cases, the analysis showed that market mechanisms, conventional command and control regulation, and community development appear to have opposite strengths and weaknesses, suggesting that institutions combining aspects of these various types of arrangements may 
work better than any approach alone. For example, the fisheries' tradable permit system in New Zealand has added co-management institutions to market institutions in a successful manner (Stern, 2011). Another example of hybrid arrangements for protecting ecosystems' services is the regulation of the Mississippi River and its tributaries. Instead of relying on a state-based top-down approach for addressing the risks of flooding and the regulation of various uses, a participatory approach was adopted that included the Corps of Engineers, the Fish and Wildlife Service, local landowners, environmental groups and academics from multiple disciplines. Consensus was reached over alternative management options and a better balance found between the various values than would have been the case in the conventional regulatory approach alone.

In this context it is important to note that a more recent review of global assessment studies, The Economics of Ecosystems and Biodiversity (TEEB, see www.teebweb.org), uses a less advanced set of methodologies, compared to the Millennium Ecosystem Assessment exercise. The TEEB explicitly recognizes the limits of monetary and quantitative valuation of ecosystem services. In addition, this report recognizes the value of local case studies, such as those that have been conducted to support the Millennium Assessment. However, the main studies reviewed in the TEEB report are quantitative cost-benefit studies that poorly integrate the innovative methodologies developed over the last decades to conduct integrated assessments. From the perspective of sustainability science, the kind of analysis produced in the TEEB report therefore needs to be more closely articulated to non-quantifiable environmental values and a transdisciplinary mode of research organization. Otherwise, as also argued elsewhere (Spash, 2011), there is a risk that the effort will remain a purely rhetorical one, with little impact on real world policy making.

A more promising initiative that directly builds upon the innovative interdisciplinary methodologies used in the Millennium Assessment is the Intergovernmental Science-Policy Platform for Biodiversity and Ecosystem Services (IPBES) (Vohland et al., 2011). The IPBES has been installed officially by a decision of the United Nations General Assembly in December 2010. The main improvement over the Millennium Ecosystem Assessment is a stronger focus on the participatory transdisciplinary dimension of the research. Nevertheless, it is still a young organization, and its effectiveness will crucially depend on the support it will receive from stakeholders and policy makers (Larigauderie and Mooney, 2010).

These models and proposals, developed in large part by ecological economics scholars, are not to be considered as new panaceas. However, they have proven to provide scientifically sound and policy-relevant knowledge for sustainability. In particular, they have shown that bringing the full range 
of voices to the table leads to a fuller scientific understanding of the socioecological interactions. Further, to the extent that agreement is found, it is reached through shared human judgement and reasonable argument based on a plurality of methodologies, rather than on the discovery of a mathematical model or a meta-ethics that unites all (Norgaard, 2009, p. 94).

\section{A decade of Earth System Science Partnerships}

A second practical application of integrated scientific approaches to socioecological interactions is the vast programme of the Earth System Science Partnerships (Lawton, 2001; Reid et al., 2010). These partnerships were established by four global environmental change programmes: DIVERSITAS; the International Geosphere-Biosphere Program; the World Climate Research Program; and the International Human Dimensions Program on Global Environmental Change. In 2001 these programmes joined forces to intensify cooperation through an overarching interdisciplinary research programme. The research communities represented in this partnership contend that the earth system now operates "well outside the normal state exhibited over the past 500,000 years" and that "human activity is generating change that extends well beyond natural variability - in some cases, alarmingly so - and at rates that continue to accelerate" (Steffen et al., 2004). To cope with this challenge, the four global change programmes have called "urgently" for an "ethical framework for global stewardship and strategies for earth system management" (Steffen et al., 2004).

Crucial to this scientific enterprise are interdisciplinary joint projects on carbon, food, water and health. In these joint projects, scientists and policy makers address problems which require collaboration between various stakeholders (for example researchers, decision makers, engineers, civil society and private sector representatives). One of the strengths of these coordinated international research initiatives is that they bring together social and natural scientists to integrate different disciplinary concepts, tools, data and methods (Ignaciuk et al., 2012, p. 150). They are operated by officers with professional research and coordination experience and supported by one major host institution, along with several regional offices.

An important example of a joint project is the project on Global Environmental Change and Food Systems (GECAFS). This project was formulated to develop a broader food security research agenda, beyond the dominant disciplinary focus of most researchers and organizations in the "food security" domain, which is on agricultural issues (Ignaciuk et al., 2012, p. 152). In this programme, food systems are conceptualized as coupled social-ecological systems, in which vulnerability arises from multiple stressors operating across different dimensions (for example temporal, spatial and institutional) and scale levels. The main lessons of the outputs of this 
programme are the relevance of adopting a complex systems approach to food security issues and the importance of a highly consultative and inclusive approach (Ingram et al., 2010). In particular, researchers recognized the need to engage with a wide range of stakeholders. Stakeholder collaborations included the strategic partnerships with key international bodies that were established in the early phase of the project, amongst which were the partnerships with the Consultative Group on International Agricultural Research (CGIAR) (Ignaciuk et al., 2012, p. 152).

Our understanding of the earth system's natural dynamics has advanced greatly in recent years, and now provides a sound basis for evaluating the effects and consequences of human/driven change. The Earth System Science partnership clearly contributed to this endeavour. The new programme Future Earth, sponsored by the International Council of Scientific Unions, is currently replacing the partnerships. Future Earth is a new 10year international research initiative that will develop the knowledge for responding effectively to the risks and opportunities of global environmental change and for supporting transformation towards global sustainability in the coming decades. Future Earth will mobilize thousands of scientists while further strengthening partnerships with policy makers and stakeholders to provide sustainability options and solutions.

The major challenge of the successful development of earth system science concerns the level of integration of the social sciences and, even more, humanities. At present, conflicting scientific cultures can impede the integration of the human dimensions of global environmental change in earth system science. The norms and mode of functioning of natural sciences have tended to dominate. However, as emphasized by the promoters of the Earth System Science partnerships (Ignaciuk et al., 2012, p. 156), without understanding "social and political dynamics, aspirations, beliefs and values, and their impact on our own behaviour, we only describe the world's physical, biological and chemical phenomena, observe and document their changes at different scales, and apply technology to secure access to resources, but would ultimately fail to ensure sustainability". In this context, they call for "interdisciplinary research that bridged disciplines and involves stakeholders" in the organization of research programmes that can contribute to solutions for a sustainable world.

\subsection{RETHINKING GROWTH FOR THE TRANSITION TO STRONG SUSTAINABILITY}

Since the publication of the first major studies of the environmental crisis in the 1970s, there has been a growing realization in national governments and 
multilateral institutions that it is impossible to separate economic development issues from environmental issues. Many forms of development erode the environmental resources upon which they must be based, and environmental degradation can undermine human aspirations for a higher quality of life and the basic right to a healthy environment for all. For instance, inequality of access to resources and poverty in developing countries leads to economic pressure to overexploit the natural resource base (WCED, 1987, p. 3 ). On the other hand, human prosperity depends on the functioning of vital life processes carried out by nature, including the stabilization of the climate, protection of watersheds and ecosystems contributing to the purification of drinking water, and the protection of nurseries and breeding grounds.

To address the interdependence between environmental and economic issues in the transition towards sustainability, scholars have shown that there is an urgent need to rethink our conceptions of economic growth. As discussed in section 1.1, because of the impossibility of decoupling between economic growth and material throughput of the economy, scientists need to consider the limits of the planet's capacity to regenerate vital resources and absorb waste in their models of economic development. Moreover, a wealth of studies show that the current economic indicators, mainly based on a measure of the monetary value of a country's market activities in terms of its Gross Domestic Product (GDP), are not a good indicator of human welfare, distributive justice or higher quality of life. However, in spite of these well-known failures of the growth indicators, they are still the dominant way policy makers and the media present progress or decline in a country's development and are the basis on which policy makers build their economic policies. This undisputed priority assigned to GDP - or the more fine-grained related indicators such as those based on national average real individual income - in politics is again well illustrated by the current media attention and public debate on the financial-economic crisis and necessary responses (van den Bergh, 2011). This attention reflects an extreme preoccupation with getting back as soon as possible to a fast GDP growth path that takes priority over limiting wellbeing impacts due to massive unemployment or degradation of ecosystems services, for example.

The scientific debate on rethinking economic growth for reaching environmental and social justice is complex and multi-faceted. So far it has been dominated by a focus on specific questions concerning alternative measurement indicators for national economies or the implementation of alternative models for post-growth economies (Jackson, 2009). Although these approaches clearly take the challenge of strong sustainability more seriously than the dominant approach focused on growth in GDP, a key issue which is still overlooked is the need for a critical scrutiny by citizens 
and stakeholders in society of the reasons why some types of growth, and some types of indicators, are considered more valuable than others (Muraca, 2012). To bridge the gap between science and society, scholars face the challenge of articulating the new approaches to growth, and the new indicators, to various institutional contexts which embody different sets of legitimate values (Thiry, 2012). This is witnessed, for example, by the difficulty in promoting an alternative approach to growth in policy circles, where the main response has been to try to save the GDP indicator, or at best to suggest some adaptations. To illustrate the contribution of sustainability science, this section reviews some of the strategies for coping with the insufficiencies of the conventional GDP indicator.

\subsubsection{GDP as the Largest Information Failure in the World}

In his overview of the debate on growth and the environment, Jeroen van den Bergh qualifies the use of the GDP indicator as the "largest information failure in the world". As he puts it:

GDP information influences all agents in the economy: consumers, savers, investors, banks, stock and option markets, private companies, the government, central banks and international organisations. Because of the misleading nature of GDP information, economic agents take wrong decisions from the perspective of social welfare. Given the many shortcomings of GDP as a measure of social welfare and the economy-wide effects of GDP information, year after year, one has to reckon with a large loss of social welfare. This is especially true in the long run, due to cumulative effects of structurally misleading information, which imply socially undesirable directions of investment and innovation (van den Bergh, 2009, p. 125).

Even though shortcomings in the use of the GDP indicator as an indicator of welfare or progress have been well documented in academic circles, it is important to repeat the critique (Stiglitz et al., 2009). Indeed the massive uncritical use of the GDP indicator by economists working in business and government, and by policy makers, educators and journalists, has led to an uncritical acceptance of this dominant framing of policies in the broader society as well. The criticism of the GDP indicator by sustainability scholars has generated a wealth of data from interdisciplinary analysis into the determinants of human welfare, prosperity and distributive justice, which are highly relevant for informing possible development paths that are built upon principles other than an increase in GDP or average real individual income.

From a technical perspective, GDP (Gross Domestic Product) is the monetary market value of all final goods and services produced in a country over the period of a year. The real GDP per capita (corrected for inflation) is generally used as the core indicator for judging the position of 
the economy of a country over time or relative to that of other countries. As the result of a set of historically important uses of the GDP (such as the determination of tax revenues for war expenditure and early econometric methods in need of aggregate data (van den Bergh, 2009, p. 122)), it has evolved implicitly, and often even explicitly, into the key measure of a country's social welfare, as witnessed in the official statistics of the OECD, the World Bank and the IMF, to name but a few.

However, empirical data does not offer any support for the use of GDP as a measure of social welfare (van den Bergh, 2011; Stiglitz et al., 2009). According to studies on subjective well-being, somewhere between 1950 and 1970 the increase in mean welfare stagnated or even reversed into a negative trend in most rich countries, despite a steady pace of GDP growth (Layard, 2005). To take one example, a study by Sheffield University prepared for the BBC showed that, even though monetary incomes in the formal market economy doubled on average between 1970 and 2000, the "loneliness" index increased in every single region of the UK that was measured. Commentators across the political spectrum agree on a social recession in the same period, evidenced by rising rates of anxiety and clinical depression and a loss of trust across society (Jackson, 2009, p. 144).

GDP, with its focus on market transactions, excludes informal transactions between people (van den Bergh, 2011, p. 885). As a consequence, GDP growth in both developed and developing countries often results from a transfer of informal activities to formal market activities, in which case the benefits that are measured were already enjoyed before. However, this transfer is considered as GDP growth, even if abandoning the informal activities leads to new market transaction costs or negative consequences that now have to be paid for, such as the increasing need to commute to work if the formal labour market grows in scale. Obviously the transition to a formal market economy also has some advantages, such as the division of labour and specialization. However, the optimal balance between formal and informal activities cannot be judged with the GDP indicator, since GDP omits the informal dimension of the economy.

Finally, natural capital depreciation is not reflected in GDP, which only measures the monetary value of the expansion of market activities. One consequence is that the substitution of basic conditions - such as space, serenity, and direct access to nature and water - by market goods - such as roads or installations for water purification - will be reflected as an increase in GDP and therefore considered as progress (van den Bergh, 2009 , p. 133).

To ensure that policy more systematically incorporates insights about what matters for real welfare, scholars have developed as set of alternative indicators that represent a clear improvement over GDP. The 
most influential example is the Index of Sustainable Economic Welfare (ISEW: Daly and Cobb, 1989). Other indicators are the Genuine Progress Indicator (GPI), the Sustainable Net Benefit Index (SNBI) (Lawn and Sanders, 1999) and the Index of Economic Well-Being (IEWB) (Osberg and Sharpe, 1998). These indicators represent a correction of the regular GDP by adding or subtracting certain partially-calculated indicators to/ from GDP. For instance, the Index of Sustainable Economic Welfare (ISEW) includes corrections for the costs of environmental protection and repair, depletion of non-renewable resources, labour inequalities and distribution of income, inter alia (van den Bergh, 2007, p. 13). The main advantage of the indicators based on the ISEW is that they attempt to correct for a wide variety of GDP imperfections in a strong sustainability framework. This distinguishes these attempts from other, more restricted alternative indicators, such as the Genuine Saving Index, which has been adopted as a central indicator by the World Bank. However, a common defect of the indicators based on the ISEW is that they would require more robust monetary valuation in order to develop into acceptable indicators of social welfare. This is in many cases impossible to attain, because of the non-monetary and/or non-market nature of many aspects of welfare.

A more promising approach seems to lie in the use of composite indexes that combine the various indicators that are considered to capture relevant aspects of human well-being. Unlike the previous types of indicators, this does not generate an overall calculated monetary value (van den Bergh, 2009, p. 125). The best-known example of this type is the Human Development Index of the United Nations, which aggregates a number of indicators: GDP per capita, life expectancy at birth, adult literacy rate, and combined primary, secondary and tertiary gross enrolment ratios in the educational system. Other composite indexes have been developed, in particular to illustrate the extension of the Human Development Index to issues of income inequality and political freedom (Dasgupta, 2001, Chapter 5). Further, to arrive at a more complete picture of sustainable development, indicators of environmental sustainability (such as those provided by the ecosystems' services approach discussed above) need to be included in the composite indexes (for a useful evaluation of ecosystems' services through the capabilities approach, see Polishchuk and Rauschmayer, 2012).

However, beyond the debate on new technical measures for quantifying welfare, scholars face the challenge of using the new indicators in various institutional contexts which embody different values (Thiry, 2012). Indeed, evidence on the role of information and knowledge for policy making shows that policy actors seldom use information as a direct input to their decisions (Bauler, 2012). This evidence highlights the importance of a 
solid understanding of the general political and institutional context as a prerequisite for indicators to play a more productive role in policy making (Bauler, 2012; Sébastien et al., 2012). One proposition that attempts to address this challenge is developed in the next section on integrated multicriteria assessment.

\subsubsection{Integrated and Multi-criteria Assessment Methods for Sustainability Accounting}

Advocates of the growth mantra have been repeating for years that economic growth is the best ally for distributive justice and a necessary condition for a high quality of life. This simplified picture is clearly contradicted by the evidence on welfare and subjective well-being collected in the context of the debate on the GDP indicator reviewed above. A common defence by growth advocates is to claim that such criticism, however necessary, leads to the adoption of an "anti-accounting" or an "anti-innovation" position. Such criticism seems to confuse the proven information failure of the GDP indicator for informing policy on the one hand and a position that would abandon informed decision making on growth and sustainability on the other. In particular, it neglects the vast literature on, and the growing experience with, possible alternatives for assessing human welfare and prosperity that can be constructed for improving the decision-making processes.

First, the criticism of GDP as a welfare indicator and its role in public debates and policy does not lead to a critique of the system of local, national or global accounts (based, for example, on the alternative indicators of sustainable economic welfare briefly discussed above (van den Bergh, 2009, p. 127)). Accounting systems provide detailed, disaggregated pictures of the flows of goods and services in the economy, which are increasingly complemented by data on informal markets, natural resources and environmental damage. Abandoning the myth of an aggregation of all these components into one single monetary indicator does not mean that this information cannot be used to improve decision-making processes on complex issues such as financial planning, economic policy and environmental management.

Therefore, abolishing GDP and the unilateral focus on the growth in monetary value of formal market transactions does not imply a plea against innovation, nor a rejection of the many benefits of formal markets, at least when these are balanced and evaluated against broader social goals and not considered as ends in themselves. Indeed growth and degrowth are not ends in themselves, but have to be assessed within broader frameworks of human welfare. For instance, according to the majority of analysts (Weaver, 2011, p. 179), growth in individual incomes is still needed 
in poorer countries to overcome poverty. By contrast, a shift away from further material growth in the already wealthy countries would help release environmental space for growth elsewhere and would allow the inequalities between countries and within countries to be reduced. Innovation is needed to bolster eco-efficiency, but frameworks must exist to enable the gains so captured to secure absolute reductions in the throughput of the global economy.

The method of multi-criteria analysis in particular aptly illustrates the contribution of alternative methods of sustainability accounting (Funtowicz et al., 2002; Vatn, 2005, Chapter 12). Multi-criteria analysis has been developed as an alternative to conventional cost-benefit analysis tools, which are more generally at the root of the scientific assessment models used to build the GDP indicator and its proposed improvements (such as the Index of Sustainable Economic Welfare). Cost-benefit analysis assumes value commensurability between the different objectives - that is the possibility of measuring them according to a common, mostly monetary, metric - and compensability - that is the assumption that a loss observed in one attribute or good can be compensated for by a gain in another (for example compensation for loss of availability of natural resources by using technical means to produce equivalent welfare benefits).

Needless to say, in the context of the analysis of strong sustainability problems, such assumptions are highly flawed. Moreover, cost-benefit analysis is based on finding the optimal solution to a decision-making problem based on the Kaldor-Hicks variant of the Pareto rule, which terms a solution optimal if the sum of the gains outweighs the sum of the costs (Vatn, 2005, p. 212). This approach ignores the value judgements involved in the distribution of benefits and, more generally, in providing the weights to the various gains to be considered, unless one presupposes a society where all individuals have identical preferences (as is often done in economic modelling (Vatn, 2005, p. 214)).

The core structure in a multi-criteria analysis is the multi-criteria assessment matrix, as illustrated in Table 3.1 for a specific problem situation: a transport issue (Vatn, 2005, pp. 339 and 344). The first step is to define a set of alternative solutions. A transport problem may be solved by building a railway, setting up a bus system or building a motorway. Next, a set of criteria is defined, where monetary costs, landscape changes, time saved, accidents, pollution and so on may be relevant. The impact of each alternative for each criterion are measured in the most relevant dimension, such as money, hours of time saved, ordinal ranking of landscape impacts and so on. If an alternative is better than all other alternatives on all criteria, we have a so-called ideal point. This is not usually the case, and the analysis leads to the definition of an efficiency set, based on all the alternatives that 
Table 3.1 A scores table for a transport problem

\begin{tabular}{llccc}
\hline Criteria & \multirow{2}{*}{ Units/scales } & \multicolumn{3}{c}{ Alternatives } \\
\cline { 3 - 5 } & & Motorway (a) & Train (b) & Bus (c) \\
\hline 1. Costs & Million euros & 20 & 40 & 15 \\
2. Time reductions (per person) & Minutes/day & 25 & 15 & 10 \\
3. Emissions & Tons/year & 1000 & 120 & 350 \\
4. Landscape effects & $+++/---$ & - & - & - \\
\hline
\end{tabular}

Source: Vatn (2005, p. 344).

are not strictly dominated by another alternative on all criteria. Finally, to be able to rank these alternatives, an explicit, value-based, weighting amongst the criteria is needed and an algorithm to rank the alternatives based on this weighting has to be implemented (widely used algorithms include MAUT (Nijkamp et al., 1990), ELECTRE (Munda, 1995) and REGIME (Hinloopen and Nijkamp, 1990)).

This short presentation of multi-criteria analysis gives only a very simple illustration of some of the basic issues involved when systematizing multiple objectives and integrating them into an overall assessment. In practice this method needs to be combined with other methods, depending on the information needs and data availability in each decision situation.

The three main approaches that have been developed so far are multicriteria analysis (Funtowicz et al., 2002; Vatn, 2005, Chapter 12), deliberative evaluation processes such as citizens' juries and consensus conferences (Vatn, 2005, Chapter 12), and integrated modelling (Boulanger and Bréchet, 2005). In addition, a combination of these approaches has often proven effective as a tool such as "deliberative monetary valuation" or "participatory multi-criteria analysis" (for an overview, see Stagl, 2012). The main advantage of these methods is that they allow a large amount of data, relations and objectives that are generally present in real-world decision making to be considered, so that the decision-making problem at hand can be studied in a multi-dimensional manner (Funtowicz et al., 2002, p. 57).

As general tools for sustainability accounting, multi-criteria analysis, deliberative evaluation and integrated modelling have demonstrated their usefulness in many situations of decision making on complex sustainability problems. One of the most prominent examples is the vast sustainability impact assessment undertaken at the EU's DG Research to assess the environmental impacts of various scenarios of trade liberalization (George and Kirkpatrick, 2007). Another prominent case, already discussed above, 
is the use of multi-criteria analysis in green national accounting (for an overview of the various approaches see Funtowicz et al., 2002, pp. 68-75). These methods cannot solve all sustainability problems by themselves, but they do provide insights into ways of arriving at political compromises in the case of divergent preferences, in particular by increasing the transparency of the choice process between various sustainability pathways. Indeed, since integrated and multi-criteria assessment methods allow multi-dimensional and incommensurable effects of decisions to be taken into account, they appear to be a promising framework for the micro- and macro-governance of the transition to sustainability under conditions of complexity.

\subsubsection{Post-Keynesian Perspectives on the Financial Crisis: Beyond Value Neutrality and the Marginalization of Systemic Risks}

The environmental impact of the functioning of the global financial system has received far less attention than the explicit pro-growth economic policies of national governments and international agencies, which have led to ever-increasing pressure on natural resources and ecosystem services. However, sustainability scholars increasingly recognize that the deregulation of the financial markets over the last two decades, which was part of a global strategy for sustaining growth by facilitating access to capital markets, is a major factor that reinforces the pressure on the environment and the social inequalities generated by the current development model (Jackson, 2009; Clapp and Dauvergne, 2011; Weaver, 2011). For instance, easy access to credit for private consumers has encouraged and facilitated private debt as an alternative to public debt, irrespective of the social and ecological consequences (Jackson, 2009). Another example is the volatility of financial markets that results from widespread speculation. This volatility has led prices for commodities, natural resources and the financial derivatives based on these to swing sharply from record highs and back down again in a way which is disconnected from any consideration of social or ecological impacts of this volatility (Clapp and Dauvergne, 2011, p. 217).

Sudden and unexpected crises such as the global financial crisis of 2008 only reinforce the short-term mentality among investors in currency markets. Similarly, the money invested in stocks and bonds through mutual funds and in other financial derivatives demands short-term gains as well. So most investment ends up with the firms that promise such gains (Clapp and Dauvergne, 2011, p. 218). Critics worry that it increasingly makes more financial sense, for example, to harvest an old-growth forest and invest the proceeds in financial markets today, than it does to harvest the forest sustainably over a number of years. Such realities prompt firms 
and the banks that back them to pursue investment projects that lead to environmental destruction in the short run, with little consideration for the long term. By operating this way, financial markets naturally tend to discriminate against firms that promote sustainable practices (Clapp and Dauvergne, 2011, p. 218).

Sustainability scholars therefore highlight the need to broaden the scope of sustainability science to include issues such as the analysis of the flaws of unregulated financial markets, the ramping problem of widespread speculation, and the systemic risks of the financial system that lead to costs for society that are not borne by the financial institutions themselves. One promising perspective for addressing these issues that has caught the attention of sustainability scholars is that of post-Keynesian macroeconomics (Holt and Spash, 2009). The framework of post-Keynesian macroeconomics emerged in response to the marginalization by neoclassical macroeconomics of the phenomenon of recurrent economic and financial crises and the neglect of the long academic legacy of earlier economists' study of crisis phenomena.

\section{Systemic failures of academic economics}

According to a set of prominent academic economists in Europe and the United States, the financial crisis of 2008 clearly highlights the systemic failure of dominant academic economics in the neoclassical vein (Colander et al., 2009). According to these scholars, the roots of the systemic failure are twofold. First, and most importantly, abstract equilibrium or nearequilibrium modelling leads to the systematic marginalization of the issue of systemic risks and instabilities in the financial system, whether by reducing it to probability accounting through sophisticated risk management models (most of which are too abstract to be compared with behavioural data sets) or by defining these risks simply as lying outside the responsibility of the participants in the market. The most well-known example of the first strategy is illustrated by the belief, originally shared by former Fed Chairman Alan Greenspan, that it suffices to introduce a sufficient number of appropriate derivative instruments to eliminate all uncertainty from the market. The second strategy can be found in the belief that it is not the job of economists to warn the public about possible misuse of their models. This can be illustrated by scholars who recognize the possibility of systemic risks, but who nevertheless consider that the concern for systemic risk should not be the concern of the banks, because of the governments' responsibility to provide costless insurance against a system-wide crash (see Krahnen, 2005 or Krahnen and Wilde, 2006 for a defence of this position).

The second systemic failure is the disconnection of economic modelling 
from other empirical analysis such as social dynamics. Indeed, neoclassical macroeconomists adopt hypotheses of social and human behaviour in their models that have been widely contradicted by empirical evidence. In particular, the assumption of a uniform "individual representative agent", who calculates the probabilities of all future happenings in maximizing his or her own utility, as the unit of analysis in financial markets, is in stark contrast to real-world social dynamics, based on interactions between heterogeneous economic agents that have different information sources, motives, knowledge and capabilities (Colander et al., 2009, p. 9). In a similar way, the scientific basis of current ideal growth rates adopted in the macroeconomic models can be queried. These are typically set at around a permanent GDP growth of 2 per cent and beyond (Vatn, 2009, pp. 130-31), but seldom substantiated by an empirically informed analysis of the limits of available natural resources (or at least their availability at low cost in the short term) and their impact on growth and post-growth options for the economy.

\section{The new neoclassical synthesis}

Notwithstanding several public reactions of embarrassment and even mea culpa within the profession (Krugman, 2009), it has been rather striking to notice that part of the profession has seen in the crisis a confirmation of the robustness and accuracy of the mainstream paradigm. Robert Lucas, the doyen of modern macroeconomics and Nobel Prize laureate, expressed such a point of view in a letter published in 2009 in The Economist (Lucas, 2009). In that letter he expressed support for the mainstream paradigm by affirming that the neoclassical framework predicts that a situation such as the global financial crisis cannot be predicted. The argument is quite straightforward:

One thing we are not going to have, now or ever, is a set of models that forecasts sudden falls in the value of financial assets, like the declines that followed the failure of Lehman Brothers in September 2008. This is nothing new. It has been known for more than 40 years and is one of the main implications of Eugene Fama's "efficient-market hypothesis", which states that the price of a financial asset reflects all relevant, generally available information.

Lucas's reasoning seems to implicitly suggest that situations such as the financial meltdown of September 2008 can only be explained on an ex post basis as the result of an exogenous shock and not as the potential outcome of an intertemporal coordination failure amongst economic agents (Leijonhufvud, 1997; Sethi, 2012) or as the result of an endogenous development embedded in a complex market economy leading to intrinsic instability (Sethi, 2012). The framework which has emerged 
from this argument is known in academic and public policy circles as the "new neoclassical synthesis".

The core theoretical apparatus of this new synthesis within the mainstream paradigm is constituted by the dynamic stochastic general equilibrium (DSGE)* model. This model assumes, amongst other things, a transaction-cost-free complete market and forward-looking economic agents modelled through the device of the uniform representative economic agent. The major problem of this model is that, despite its many refinements, it is not based on, or confirmed by, empirical research or behavioural hypotheses. Rather, the assumptions explicitly result from the adoption of microeconomic assumptions on markets that are always in equilibrium, irrespective of the economic cycle. These assumptions are a necessary theoretical construct for merging macroeconomics with the Walrasian dynamic equilibrium approach as updated and formalized by Arrow and Debreu (1954; De Vroey, 2009; Blanchard, 2000). This coup de force produced a destabilization of the classical conception of the role and effectiveness of fiscal and monetary policy for promoting welfare and employment in macroeconomics, and provided microeconomic foundations to the monetarist offensive based on stabilization of the so-called economic fundamentals such as interest rates and inflation levels.

This framework constitutes the backbone of the new generation of medium-scale models under development at the International Monetary Fund, the Federal Reserve Board, the European Central Bank (ECB) and many other central banks. It has also provided the theoretical underpinnings to the stability-oriented strategies to counter inflation adopted by a majority of central banks in the industrialized world (Galí, 2008).

However, in spite of the widespread use of this theoretical model, an increasing number of scholars recognize the inherent limits of this approach (see the discussion in Padilla, 2012). First, the conception of uncertainty underpinning DSGE models is one where stochastic processes are characterized by the ergodicity assumption. The ergodic axiom stipulates that at least some states of a system will recur in the future - whether in a probabilistic or exact way (North, 2010, p. 19) and therefore the future is predetermined by existing parameters. Consequently the future can be reliably forecast by analysing past and current market data to obtain the probability distribution governing future events. In brief, we are never disappointed in any other way than when we lose at roulette (where we can still calculate average expected probabilities), since "averages of expectations are accurate" (Muth, 1961). However, as also discussed in section 3.4.2 below, such a hypothesis is clearly invalidated in open and complex coupled socio-ecological 
systems, where unique future events occur that cannot be related to an extrapolation of existing data.

Second, to make this model analytically tractable in mathematical calculus, researchers assume one uniform representative economic agent, who uses one specific probabilistic calculus to determine his or her future rational expectations. As explained by Rajiv Sethi (2012), this is a consequence of the overall equilibrium framework. According to Sethi, equilibrium in an intertemporal model requires not only that individuals make plans that are optimal and conditional on their beliefs about the future, but also that these plans are mutually consistent. In such a framework, largescale asset revaluations and financial crises, from this perspective, arise only in response to exogenous shocks and not because many individuals come to realize that they have made plans that cannot possibly all be implemented (Sethi, 2012).

\section{An example of an interdisciplinary framework for macroeconomics}

In order to build a more empirically sound and politically relevant model, post-Keynesians over the years have developed a different approach which can account for the problems of widespread speculation and systemic risks in the financial system (Holt and Spash, 2009, pp. 3-4). In particular, they have developed a notion of social rationality, in which habits and herd behaviour can create bubbles and lead to recurrent crises in the absence of regulated financial markets. Using path-dependent models, these scholars explain the persistence of sub-optimal situations, including persistent high unemployment in developed countries. Post-Keynesians have also emphasized that the future is uncertain, rather than known with some probability distribution, which has led them to stress the role of government policy and regulation in order to cope with the unforeseen consequences of economic choices.

The various insights of post-Keynesian economics are directly relevant to the debate on the post-growth economy and the regulation of financial markets with the view to implementing the vision of strong sustainability. For example, James Juniper (2009) and Jerry Courvisanos (2009) use the emerging macroeconomic framework of post-Keynesian thinking to bring out the consequences of uncertainty in connection with business decisions on environmental innovation and investment for sustainable development. They show how group behaviour can have a cumulative effect: it can lead to major breakthroughs in environmental investments, or it can result in long-term damage to the environment. Another important contribution of post-Keynesian economics has been to incorporate the classical concepts of class conflict over the annual social surplus, and the importance of real physical costs into economic models of production. As shown by Gowdy 
et al. (2009), theoretically consistent production models based on the work of Pasinetti, Rymes, Sraffa and others, using vertically integrated inputoutput relationships, have proved to be powerful tools in characterizing the real structure of modern economics. A case in point is Pasinetti's formal theory of transformational growth, where only the increased fulfilment of vital human capabilities counts as growth, while environmentally destructive production practices and imperialist military spending is discounted as negative growth (Pasinetti, 1981). This model is an elegant illustration of how sustainability can be factored directly into alternative macroeconomic models.

The core ideas of post-Keynesian macroeconomics that emerge from this literature can be characterized as follows (Holt and Spash, 2009, p. 3):

- the recognition of the prevalence of uncertainty (recognizing the prevalence of matters where there is no scientific basis on which to form any calculable probability whatever);

- the recognition of the historically path-dependent nature of economics (instead of supposing that the system is heading towards an equilibrium);

- the impact of social rationality on individual decision making; and

- a focus on growth in the income of individual agents striving to satisfy their needs instead of a focus on the price system (which is no longer considered as an appropriate information mechanism revealing information for individual decision makers, but as one affected by speculation and market power).

Many of these core ideas offer great opportunities for sustainability science, especially by adding new tools to study important issues, such as the instability and intragenerational distribution issues of modern capitalism. This is despite the fact that the focus on income growth in postKeynesian thinking is at odds with the need to integrate the limits of the planet's resources into the analysis of human agency and economic development. Nevertheless, this drawback of the focus on expanding demand in Keynesianism is increasingly recognized by post-Keynesians themselves and, as seen above, even post-Keynesian scholars have started to integrate the problems of environmental sustainability into their framework (see Mearman, 2005 for an overview).

One of the key consequences of the innovations introduced by the postKeynesian framework is the requirement to develop an interdisciplinary research programme related to the role of expectations and heterogeneous processes of belief formation and competing narratives on the future, under the constraint of non-ergodic uncertainty. Such a programme must 
arise within the borders of macroeconomics and emerge from the need to overcome the epistemic closures highlighted above. Macroeconomics needs, in that respect, to build an open-ended interdisciplinary research programme aiming inter alia at creating a broader spectrum of stylized facts and analytical tools, where not only interdisciplinary economic approaches such as Veblenian evolutionary economics (see section 3.3.2 below), but also disciplines such as social psychology, agent-based models, anthropology and organizational sociology play a crucial role.

\subsection{ADDRESSING DEMOCRATIC CHOICE IN SOCIO-TECHNOLOGICAL TRANSITIONS}

Sustainability scholars and policy makers widely recognize that innovation in its various forms has a crucial role to play in realizing the kind of transformative change needed to address the interdependence between environmental and economic issues (Stamm et al., 2009). In this context, the idea that we need to fundamentally change research, technology and innovation policy has continuously gained support in the debates about sustainable development and, more recently, in the European debate on Grand Challenges (European Union, 2008). Indeed, to realize long-term transformative change, more will be needed than individual product or process innovation at the level of the firm. Rather, comprehensive system innovations should be implemented, which can generate novel configurations of actors, institutions and practices that bring about new modes of operations of entire sectors or systems of production and consumption (Weber and Rohracher, 2012, p. 1037).

Despite a growing body of literature on the complex "hybrid" sociotechnological nature of innovation, many citizens, policy makers and scholars still put the main emphasis in their support for innovation on "technical fixes", and hardly deal with this more fundamental type of transformative change of the modes of innovation that are needed for the transition to sustainability. Even prominent post-growth scholars such as Tim Jackson (2009) (focusing on investment in clean technologies) and Jeremy Rifkin (2011) (proposing a massive conversion to decentralized solar energy) put great emphasis on technical fixes or green investment to overcome the sustainability crisis, without explicitly questioning the many complex and discrepant positions over knowledge, values, meanings and interests that define the real-world trajectories of scientific research and technological innovation.

Against this background, leading scholars of "science, society and technology" suggest that dominant assumptions about science, sustainability 
and progress need to be rethought (Pauwels, 2011, p. 113). They argue that notions such as scientific "object", "safe limits" of technologies, or "risk" for example are in themselves ambiguous and in need of further debate (Wynne, 2007). Additionally, the concept of sustainability-oriented innovation systems (Stamm et al., 2009) will always include an array of complex normative meanings that lose form by being reduced to questions of a "technological fix".

The discussion in the scientific community around the new frontier science of synthetic biology aptly illustrates the hybrid socio-technological nature of scientific research and technological innovation (Pauwels, 2011, pp. 114-15). Synthetic biology is presented in the US press coverage as a key solution to address the challenges of sustainable development, by developing customized organisms with powerful new capabilities. These customized organisms can be programmed to fight diseases and create new materials for manufacturing or producing an abundant source of clean, renewable energy (Ballon, 2008). However, opposite perspectives emerging from the civil society are voiced in the press to contest this. Fearing that artificially produced organisms will threaten ecosystems, environmental groups have condemned synthetic biology as a grave biosafety threat to people and the planet (Ballon, 2008). Moreover, several voices from the academic sector have warned that the technology may develop in an unsustainable way with regard to environmental and social concerns (Rodemeyer, 2009). As a consequence, there are serious social, ethical and safety questions surrounding this new and promising technology (Pauwels, 2011 , p. 133). The purpose of these questions is not to stifle innovation processes or cause undue alarm, but rather to expand awareness on what effects synthetic biology could have on both the political systems and our conception of humanity as a whole (Pauwels, 2011).

To implement long-term transformations of socio-technological systems, sustainability scholars and policy makers need to understand the systemic interconnections of the many social trajectories of technological innovation, ranging from risks for the environment and ecosystems, controversies between scientific communities, economic parameters, policy-making processes and cultural values and concerns. In response to these challenges, science and technology scholars have developed various theoretical frameworks for promoting innovation in the transition to sustainability (such as transition management, strategic niche management or the multilevel perspective on socio-technological transitions). In addition, evolutionary economics scholars have deepened our understanding of long-term historical processes and their role in problems of persistent technological lock-ins. The following section reviews the key features of these promising fields of transdisciplinary 
research and assesses its contribution to the research agenda of sustainability science.

\subsubsection{From Firm-level Innovations to Sustainability Transitions}

\section{The innovation systems' perspective as a thin baseline}

The standard rationale for policy intervention in the conventional firmlevel approach to innovations is based on market failure arguments as developed by Arrow (1962). The main argument is that a fully competitive, decentralized market system will provide a sub-optimal level of investment in knowledge development as a consequence of the public good character of certain types of knowledge, potential spillover effects, and the short time horizon applied by market actors in their investment calculations (Weber and Rohracher, 2012, p. 1041). This underinvestment justifies both public subsidies for basic knowledge development and the shaping of specific protection and incentive structures such as the system of intellectual property rights. In addition, innovation scholars recognize that mechanisms are needed to improve the structure and the dynamics of the innovation systems, for instance by fostering interactive learning between firms and universities or building adaptive capacities within firms (Weber and Rohracher, 2012, p. 1042).

This innovation-system perspective has been widely accepted as the basis of technology and innovation policy. For instance, the Organisation for Economic Co-operation and Development (OECD) uses the national innovation concept as an integral part of its analytical perspective (Sharif, 2006). The OECD facilitates the diffusion of good practice of research, technology and innovation by providing statistics, analysis and recommendation for its members. Intellectual property rights, innovation-related tax incentives and the facilitation of closer university/industry relationships are part of the standard repertoire of proposed policies that are widely adopted by OECD member countries.

The market failure and systems failure arguments of the innovationsystems perspective are useful and valid, but they are confined to assessing the structural deficits of innovation systems, which fall short of addressing the process of transformation of the socio-technological systems needed for the transition to strong sustainability. Transition scholars, such as Weber and Rohracher (2012, pp. 1042-4), have identified a set of challenges for governing the sustainability transition that are not included in the innovation-systems perspective.

For understanding the long-term transformative processes of innovation in socio-technological systems, a first challenge for sustainability scholars is to address the question of the overall normative orientation of 
the transformative change. This goes beyond analysing how to generate new innovations as efficiently and effectively as possible. The direction is defined, for example, by the identification of major societal problems or challenges and the development of so-called "visions" by coalitions of key players. Second, the long-term character of transformative change, associated with the uncertainty surrounding this process, has to be addressed. This requires the processes of monitoring to be analysed in particular with respect to normative goals, and adaptation strategies to be developed. A key research question for transition scholars in this context is therefore to examine how socio-technological systems can develop the ability to monitor, to anticipate and to involve actors in open-ended processes of adaptive self-governance. Third, coordination problems at multiple policy levels, and amongst the broader network of users and stakeholders, need to be addressed, above and beyond the focus on coordination problems of firms, universities and other research and development actors.

\section{Reconnecting innovations and social practices}

Scholars of socio-technological systems have developed various approaches to address these questions. In spite of the many specific models and theories developed by transition scholars, these approaches can be analysed as models of socio-technological policy arrangements with two core concerns (Boulanger, 2012): first, developing a conceptual framework for understanding societal changes at the level of socio-technological systems (called the multi-level perspective on transitions) and second, developing a model of governance of such systems (called transition management).

The multi-level perspective aims to analyse long-term transformative changes in complex socio-technological systems. In this approach social change is analysed as the outcome of the dynamics between three systems, which form a nested hierarchy (Boulanger, 2012; Weber and Rohracher, 2012; Geels and Schot, 2007): first, the system of technological niche innovations, which functions as a source of variety, test bed and an "engine for change"; second, regimes (such as the energy systems) providing structures, cultures and practices shared by all the actors in the socio-technological system; and, third, socio-technological landscapes, which represent an exogenous environment of slowly changing cultural norms, values and structures beyond the direct influence of niche and regime actors (such as increased awareness of and concern for sustainability). In this approach, transitions are triggered by a combination of niche innovations, pressures from changes in the landscape and problem solving at the regime level as depicted in Figure 3.2.

The policy aspect of transition theory is usually called transition management. It consists of a methodology for initiating and/or steering 
Increasing structuration

of activities in local practices

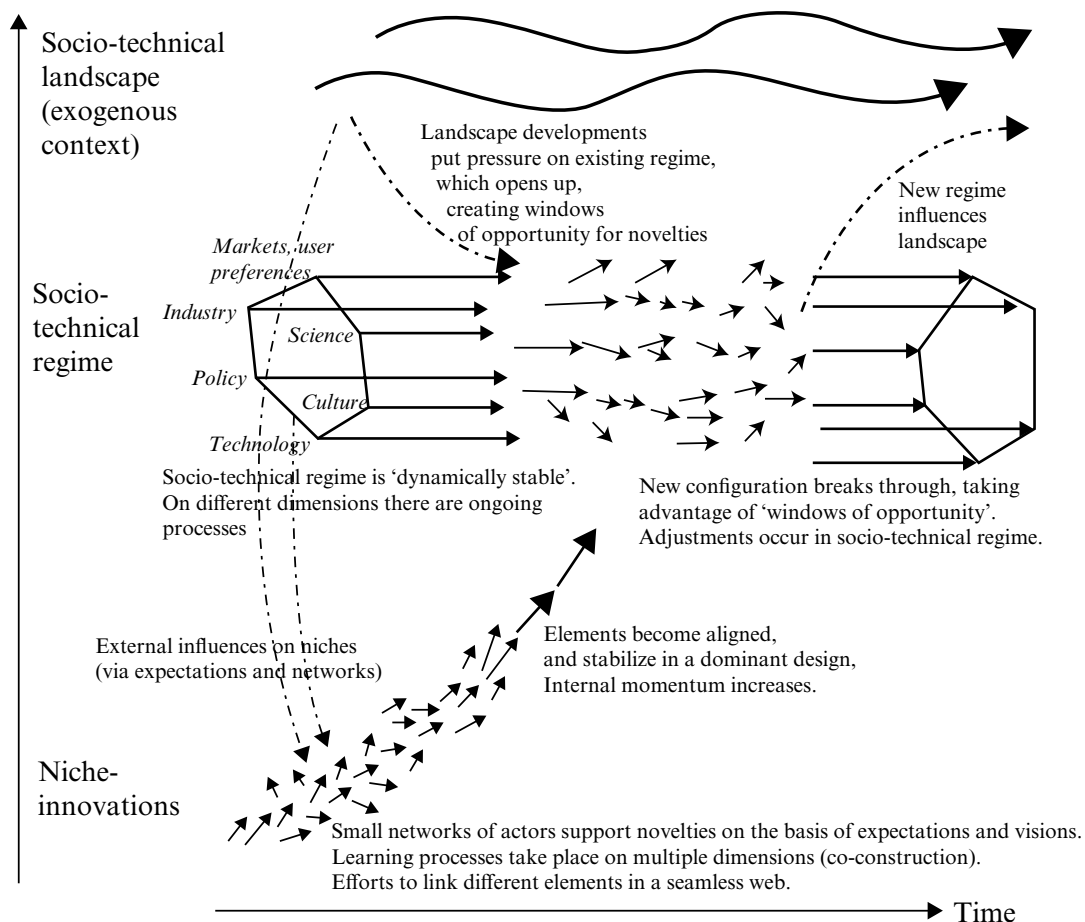

Source: Geels and Schot (2007, p. 401).

Figure 3.2 Typology of socio-technical transition pathways

ongoing transitions so that the new socio-technological regimes will be compatible with sustainable development (Boulanger, 2012). The main elements of the process are the identification of a group of frontrunners who can work out an integrated problem and system analysis, a process of envisioning mid- to long-term future scenarios, the conducting of transition experiments, and continuous monitoring and evaluation by all the actors involved.

This transition approach (with its various sub-fields and methodology) is a promising way forward to overcome the shortcomings of the firm-level innovation perspective and the illusion of easy automatic adoption of "technological fixes" for addressing the challenge of strong sustainability. One of the main contributions of this approach to 
sustainability research is the development of a practice of transdisciplinary research for sustainability (Boulanger, 2012). As pointed out by Grin et al. (2010, p. 107),

our transdisciplinary approach [to transitions] does not only rely on the input of scientific knowledge and expertise, but also on participatory research. Because transition research also seeks to contribute to a more sustainable society, action research plays a prominent role as well. The exchange of knowledge between scientists and societal actors to which our approach gives rise does not follow a linear path but rather entails a societal process of co-production between the parties involved.

For example, in the Netherlands a small network of university researchers and policy consultants produced the original transitions storyline (Rotmans et al., 2001) and developed the research into socio-technological transitions in close cooperation with policy makers.

The transition approach was adopted in 2001 by the Dutch Government as the appropriate language for its Fourth Environmental Policy Plan and is currently used in several other countries (Germany, UK, Finland, Belgium and Switzerland, to name just a few). However, transition approaches, even if they have mainly been used in a sustainable development context, essentially develop a general theory of socio-technological transitions, and not a theory of strong sustainability or integrated socio-ecological relations. Indeed, even though this approach has been predominantly used in a sustainable development context, the approach in itself does not have a conceptualization of sustainable development (Boulanger, 2012). This lacuna has led to increasing frustration and tensions, for example in a major initiative on transition in Flanders, in the domain of waste and sustainable materials, where the initial dominant orientation in terms of reduction of waste materials has been overtaken by actors focusing primarily on the creation of a market for the supply of waste as secondary products (Paredis, 2011).

Along with science, technology and society approaches more generally, transition approaches are useful tools for sustainable development but deserve to be further explored in more specific ways in order to contribute more fully to the key principles of sustainability science highlighted in this book. In particular, the socio-ecological interactions and dependencies between the socio-technological and the ecological system should be directly integrated into the analysis itself (instead of appearing on the margin as an external motivational factor or a set of framework conditions).

One promising way forward in this direction is the attempt to connect transition research to other disciplines that have a more long-standing 
experience with interdisciplinary analysis of socio-ecological relations (such as geography). For example, to study energy transition policy in urban areas, which integrates the concern for reconnecting the economy of the city with its local natural resource base, the city and its region can be analysed as a place where interactions between different transition processes take place and thus synergies and hindrances between different technological transformations may become transparent. As suggested by Coenen et al. (2012, p. 976), in such a perspective cities and regions can be considered as major nodes in wider networks of actors that may simultaneously develop their local resources and access and influence resources at different spatial scales. In this respect, as Coenen also suggested, it is encouraging that transition research has started to engage increasingly with urban policy-makers and stakeholders to account for a more coherent and multi-scale perspective on sustainability transitions (Loorbach, 2007). In a similar way, Marina Fischer-Kowalski develops an innovative approach that creates a stronger connection between transition research and the ethics of strong sustainability. This so-called "metabolic" approach to transitions combines the analysis of transitions between socio-technological regimes with an analysis of the average individual energy need in each of the regimes (Fischer-Kowalski and Rotmans, 2009).

\subsubsection{The Contribution of Veblenian Evolutionary Economics to Addressing Long-term Historical Processes of Innovation}

The multilevel perspective on transitions discussed above can be usefully combined with the framework of Veblenian evolutionary economics, which can easily accommodate inter-disciplinary approaches to sociotechnological transitions (in particular, given that Veblen himself was both an economist and a sociologist and was inspired by various disciplines including biology, psychology and social philosophy). In addition, given the need to integrate ecological analysis more directly into the study of socio-technological systems, a promising perspective in this context would be the coupling of these insights from the framework of Veblenian evolutionary economics and the multi-level approach to transition management with the general perspective of ecological economics. Such a combined approach would provide a more promising way forward (both theoretically and on an applied basis) to governing socio-technological transitions than the current systems-innovation perspectives.

The field of technological innovations and the problems of technological lock-in aptly illustrate the contribution of evolutionary economics to sustainability science. This field has generated a great deal of research since the first publication of "An evolutionary theory of economic 
change" (Nelson and Winter, 1982). Although the contribution of Nelson and Winter to the field of evolutionary economics is immeasurable (it is often quoted as the book that marked the birth of modern evolutionary economics), this school of thought in evolutionary economics (i.e. neoSchumpeterian and Simonian) does not appear as readily useful for a sustainability science perspective on technological innovation as, for instance, the literature on path-dependence, which is inherited from the works of Thorsten Veblen.

The key contribution of the historical Veblenian evolutionary economics to the study of long-term transition processes is to provide a radically distinct perspective with respect to the ahistorical and mechanistic reductionism characterizing mainstream economics. Indeed, as clearly shown by Veblen and his followers, the Cartesian/Newtonian influence on economics was decisive (Veblen, 1898; Maréchal, 2007). It led to a model based on "mechanistic reductionism". Indeed, not only does this reductionist model explain whole economies on the basis of one sole agent/firm - through the assumption of the representative agent - but the characterization of that agent/unit is reduced to its mechanical properties, as illustrated by the Homo Oeconomicus construct. As claimed by Foster (1997, p. 432), the Cartesian/Newtonian legacy also means that we are left with a linear and ahistorical paradigm in economics in so far as it does not "depict a process unfolding in history".

In order to overcome the shortcomings of this model for the study of long-term transition processes, evolutionary economics introduced two pregnant ideas: the multilevel nature of economic evolution; and pathdependent processes. As Witt (2004, p. 124) puts it, the consequence of the approach adopted in evolutionary economics is that "the question is not how, under varying conditions, resources are optimally allocated in equilibrium [. . .]", but rather "why and how knowledge, preferences, technology and institutions change in historical processes, and what impact these changes have on the state of the economy at any point in time".

The inherent inertia that goes together with a path-dependent process can be illustrated by the famous QWERTY case (David, 1985). Although this keyboard design was developed for deliberate and justified reasons (i.e. to avoid the letter bars clashing on a typewriter), the main criteria for this decision are no longer relevant in today's computer era. In spite of this, the design is still the most commonly used today, although there are other, more efficient, designs available. This is what Foray (1997, p. 745) called the "persistence of obsolete intentions".

The example of technological lock-in is but one instance of how evolutionary economics in a Veblenian perspective can usefully inform sustainability science. It is worth noting, however, that evolutionary economics 
was not intended to provide an answer to the challenge of the transition towards sustainable societies. In this sense, it is not prescriptive of any direction. What evolutionary economics can be useful for is providing a radically distinct perspective on the crucial issue of economic evolution and human behaviour. It can serve as a scientifically robust, philosophically sound and empirically appropriate framework to deal with complex socio-economic issues in an alternative manner to that which prevails in mainstream analysis.

Indeed, as the model of mainstream economics has been strongly criticized by many different scholars from distinct disciplines and for distinct reasons (among them the puzzling presence of some degree of altruism in human behaviour that cannot easily be accommodated by mainstream hypotheses), decision makers are increasingly eager to learn from alternative perspectives. This is especially true in environment-related domains where the issues at stake often display inherent characteristics (complexity, irreversibility, deep uncertainty, etc.) that challenge core economic assumptions, and which render mainstream economic theory inappropriately equipped to deal with the problems posed. More precisely, evolutionary economists show that what is needed, given the failures of economics to build a theory of long-term socio-economic transitions, is a framework resting on a different view of individual rationality and allowing for richer and more complex causal relationships to be accommodated.

Veblen made an important contribution to the development of such a model, which is highly relevant to sustainability science. In particular, he developed a more realistic model of human behaviour centred on the notion of habits and social learning (cf. Maréchal, 2010). Resorting to habits is undoubtedly a rational way to proceed given the constraints of daily life and the obvious limitedness of cognitive resources. This alternative approach for understanding rationality of behaviour is in sharp contrast to the utilitarian approach, which considers that every economic decision can be analysed as a discrete situation. One application of the approach of Veblen is the importance of destabilising habits prior to providing individuals with an incentive to make punctual decisions, such as implementing a subsidized energy-efficient investment. In particular, contemporary research has shown that an incentive, such as providing an energy subsidy, is processed differently in a case with a perturbation of habits compared to a case without a perturbation of habits (Maréchal, 2010).

It follows from this brief discussion of Veblen's perspective that economic phenomena cannot be adequately studied without accounting for their historically contingent nature both through path dependency and through their interlocking with the wider context in which they occur. 
Applying this argument to the issue of how environment-friendly technologies evolve, inevitably leads to the idea that our economies need to address the institutional and cultural aspects of economic choices in order to escape from the current lock-in of the carbon socio-technological system (Unruh, 2000; 2002; Maréchal, 2012).

\subsection{BEYOND INTERDISCIPLINARITY: THE NEED FOR STRONG SUSTAINABILITY ETHICS WITHIN A TRANSDISCIPLINARY ORGANIZATION OF THE RESEARCH PROCESS}

The research programmes discussed in this chapter all attempt to overcome the insufficiencies of "value neutral" and "ivory tower" modes of organization of scientific research. For example, the case of the flooding of the Mississippi river shows the need to integrate values of various communities of interests when elaborating ecological management scenarios (see section 3.1.3). To address this challenge, the Fish and Wildlife Service adopted a participatory transdisciplinary and integrated ecological economics approach. In this manner, the service was able to address the problem in a more successful way, compared to previous attempts based on top-down bureaucratic approaches using so-called neutral scientific expertise gained from biophysical models.

Many researchers recognize the failures of mono-disciplinary, valueneutral science to tackle the main challenges for governing coupled socialecological systems, which are related to persistent uncertainty over future outcomes and the entanglement of facts and values. As seen through the research programmes discussed above, researchers have attempted to integrate the three core dimensions of sustainability science to overcome these failures.

\subsubsection{The Role of Ethics of Strong Sustainability and Involvement of Social Actors in Sustainability Science}

The first dimension, interdisciplinarity, is present in all the sustainability research programmes discussed within the scope of this book. Indeed, most of these programmes were first developed to overcome persistent failures in existing mono-disciplinary approaches. The latter are now well documented in the scholarly community. Examples discussed above include the dramatic failures generated by the use of mono-disciplinary environmental models in the management of the Everglades in Florida; the continuing use in economics, even in academic circles, of the GDP 
indicator as a measure of human welfare; and the failure to take into account social dynamics beyond firm-level processes in the analysis of technological innovations for sustainability. In response to these failures, sustainability scientists over the last two decades have developed interdisciplinary approaches such as multi-criteria assessment, ecological economics modelling and multi-level transition management, amongst others, that can better address the specific features of sustainability problems.

As shown through the analysis in this book, interdisciplinarity alone is not sufficient for realizing the purposes of sustainability science. For example, irreversible loss of non-renewable natural resources such as genetic resources and ecosystems clearly restricts the range of possible actions of present and future generations, which has ethical implications that reach beyond the hypothetical-deductive analysis of the complex socio-ecological dynamics. In this respect, just setting up interdisciplinary research programmes, without an explicit framework for implementing a strong sustainability ethics, will not necessarily lead to the expected transition to strong sustainability. Nevertheless, the need to integrate a strong sustainability ethics does not imply the adoption of a uniform ethical position. Rather, a common framework for discussion is needed in order to assess and evaluate the available arguments leading, for example, to the choice of certain thresholds of use of natural resources. Examples discussed in this book of efforts in that direction are the integration in transition management studies of environmental impact studies of the technological choices, both regionally and globally (see section 3.3.1), or the discussion on the level of solidarity between present generations in the calculation of allowable carbon footprint per capita (see section 2.1).

Further, as stated in the introduction, the explicit goal of sustainability science is to produce basic and applied research that can make a contribution to solving practical problems and assist societies in their transition to strong sustainability. As such, it has been qualified as strategic or transformative science. Building ethically justified frameworks for interdisciplinary research will only be effective for supporting societies in their transition to sustainability if such a framework is translated into a practical process for reconciling multiple values and multiple perspectives on problem framing. Many cases show the failures to bridge the sciencesociety gap in sustainability research without explicitly constructing a participatory transdisciplinary research process, which directly involved the social actors in the knowledge gathering and the building of the research design. For example, the innovation systems approach does not develop a transdisciplinary approach to tackling the social acceptability of new technologies and social learning on their effective use for more sustainable behaviour. As a result, the approach fails to support a broad social 
transition to sustainable production and consumption even if it increased our understanding of firm-level technical innovations for sustainability (see section 3.3.1). In contrast, transition theory scholars developed various analytical approaches by directly involving the stakeholders of the technological transition paths. A prominent illustration of such collaboration is the way the transition management scholarship has been organized in close collaboration with policy officials and technology stakeholders in the Netherlands.

The key message that comes out of the review of the literature of leading sustainability approaches therefore is the need to combine the three dimensions of sustainability research. On the one hand, in order to reach the goal of sustainability science as a transformative science, interdisciplinarity alone is not sufficient. To achieve these goals, interdisciplinarity needs to be combined with an ethical framework that explicitly addresses strong sustainability and with a transdisciplinary organization of the research process. On the other hand, transdisciplinary collaboration without systematic interdisciplinary research is also insufficient. Indeed, a transdisciplinary process might lead to the creation of a satisfactory ad hoc solution to a sustainability problem, but the latter can hardly be qualified as sustainability science. One example of a contribution to strong sustainability that was not organized as a systematic interdisciplinary sustainability research programme is the sustainability plan of the city of Rome, which has been developed with the contribution of the school of architecture of the Sapienza University in Rome. This research support was organized with a multi-stakeholder approach, but was not designed as a systematic sustainability research endeavour. Although this plan certainly has provided an important set of possible solutions for the city of Rome, it is still organized as decision support or consulting, rather than sustainability research. In contrast, the University of Tokyo also built a partnership with the local authorities for multi-stakeholder research on low-carbon economies. In this latter case, this research programme had both a transdisciplinary and systematic interdisciplinary research dimension. The contrast between these two examples will be discussed in some more depth below in section 5.2.3.

\subsubsection{Sustainability Research in Economics}

The need to combine the three core dimensions of sustainability research has been analysed in more depth in this book in the particular case of the interdisciplinary approaches developed within economics. Most researchers in economics are involved in the conventional mono-disciplinary approach to science inherited from the mathematical law-like model of 
Newtonian physics (Mirowski, 1989). This approach is by far the most dominant mode for organizing economic research and leads to a clear separation between facts and values, a focus on quantified variables and ultra-specialized expertise. As in other scientific fields, the mathematical law-like model for practising science has proved very productive in situations of high predictability of outcomes and well-identified and quantifiable problem situations. However, this conventional approach has clearly proved inadequate for addressing the connections between economic constraints, the environmental limits of the planet and sustainability ethics.

Advocates of the mono-disciplinary and expert-led approach to economic modelling for sustainability research put forward three main arguments in favour of their position. The first argument is based on the so-called fact/value dichotomy and maintains a strict separation between research into factual matters and research into the formulation of ethical orientation, relating to the objectives of social justice and animal welfare, for instance. David Hume articulated this famous dichotomy in the eighteenth century by stating that factual/value-oriented arguments can only be validly derived from other factual/value-oriented statements, respectively. One consequence of such a strict separation is that, since economic modelling deals with theories that account for matters of fact, it should not consider ethical issues in the discussion of the research hypotheses and in the choice of research methodologies.

However, the strict separation thesis, attractive as it may be at first sight, does not withstand closer scrutiny (Putnam and Walsh, 2012). Even in conventional general or partial equilibrium modelling, assumptions with normative implications play a role in the practical computation of the outcomes of the model. A well-known example is the use of Pareto optimality as a measure of economic efficiency, which is based on reaching a state of allocation of resources in which it is impossible to make any one individual better off without making at least one other individual worse off. The work by Nobel laureate Amartya Sen provides another illustration of the importance of normative considerations in the field of welfare economics and social choice theory. Indeed, as he shows in his influential work entitled The Idea of Justice (Sen, 2009), any reasoned comparison between social choices depends on a set of prior hypotheses about the kind of information that researchers consider relevant in judging a society and in assessing justice and injustice. This can be illustrated with three major approaches to social choice: utilitarianism, pioneered by Jeremy Bentham, concentrates on individual happiness or pleasure; resource-based approaches focus on individual income or wealth; and the capability approach focuses on the capability to do things that a person has a reason to value. These normative backgrounds determine the general way researchers will collect and 
compare individual social advantages prior to making any mathematical modelling choices and independently of more specific formulas adopted to assess specific policies within the chosen model framework.

As a consequence of this entanglement of normative and factual considerations (Putnam, 2002), the strict separation between facts and values cannot be maintained in economic research. To guarantee a broad scientific understanding of the sustainability issues at stake, sustainability researchers therefore need to clarify the normative background choices, whether in terms of data gathering, the elaboration of hypotheses or the calculation of outcomes (Popa et al., 2014). In the case of sustainability research in economics, the key normative issue to be discussed is the degree to which the limits of the earth's resources and the earth's ecological carrying capacity should be taken into account in economic modelling, by considering in particular the impact of environmental degradation on human well-being and ecosystem health. Even though the way in which this issue is approached differs widely, depending on philosophical orientation, researchers in environmental ethics converge on the need to develop at least a certain form of earth ethics (Callicott, 1999; Rifkin, 2011). Such an ethical perspective can be formulated in general terms as the duty to preserve - whether for its own sake or for the direct satisfaction or utility it provides to human beings the integrity, stability and beauty of the living ecosystems of planet earth. More recently, researchers have shown that this ethical concern is not just motivated by reflections on the present ecological crisis, but is also closely related to other human values such as aesthetic considerations or the preservation of the cultural diversity of life forms.

A recent publication in the journal Nature by Johan Rockström and colleagues (Rockström et al., 2009) circumscribes some minimal practical implications of the adoption of such earth ethics, particularly from an anthropocentric viewpoint - which relates the preservation of the earth's living ecosystems to its contribution to human well-being. In an attempt to define the biophysical preconditions for human development, Rockström calculates a set of safe limits outside which the earth system cannot continue to respond smoothly to the changing pressures. Above these thresholds the earth system is likely to react in non-linear and abrupt ways. Three earth system processes have currently already reached dangerous levels beyond the thresholds and need immediate action to prevent the likely collapse of some life-supporting ecosystems, which would mean biodiversity extinction, nitrogen flow into fresh and ocean waters and climate change. Other thresholds of earth system processes have still been kept within safe limits at this stage, such as ozone depletion or global fresh water use.

Obviously, determining a safe distance from the thresholds of stability of the earth system involves normative judgements. These judgements should 
consider, inter alia, how society chooses to deal with risk and uncertainty, and how to deal, from a normative perspective, with the possible consequences of disrupting some of the earth's living ecosystems for certain human populations that do not have the means to cope and for other non-human living creatures. Some of the advocates of mono-disciplinary and expert-led approaches might object that making the entanglement of factual and normative statements explicit in sustainability research on economics will lead to a dogmatic and biased approach that is not compatible with scientific open-ended and critical practice. Even though such fears are clearly not unwarranted, this is not a necessary consequence of the transdisciplinary approach to sustainability science developed in this book. Instead, in the formulation of various aspects of earth ethics, researchers can rely on contemporary approaches of ethical objectivity in social and environmental ethics. In these approaches, ethical objectivity is understood as the result of an ongoing public debate among a wide diversity of participants (Putnam, 2009). In this debate, positions are regarded as being objectively valid if they can survive challenges from informed scrutiny coming from a wide variety of viewpoints and outlooks, based on diverse experiences. This includes, in particular, the possibility that there remain contrary positions that simultaneously survive and that cannot, as stated by Amartya Sen, "be subjected to some radical surgery that reduces them all into one tidy box of complete and well-fitted demands" (Sen, 2009 , p. 46). On the contrary, researchers involved in transdisciplinary research practice might take such a situation as the starting point to envision more than one social and institutional pathway to put ethical visions into practice in different communities.

This deliberative and critical perspective on earth ethics fits nicely into the overall dynamics of the scientific methodology, even though it is not based on experimentation and mathematical modelling. However, it shares the general epistemic values of science such as public dialogue, critical scrutiny and openness, with an additional concern to involve less resourceful and socially disadvantaged actors in the debate. Indeed, even though the process is oriented towards increased objectivity, participants remain open to including future arguments from all human experiences and social innovations. One consequence of this approach to earth ethics is to include a broad set of arguments related to the motivations of human practice in the debate, such as emotional/behavioural considerations, aesthetic visions or institutional realities, as these all play a role in determining the relationship that morally autonomous human beings develop with their natural environment (Sen, 2009, pp. 49-51; Muraca, 2011). From this perspective, therefore, the main issue of the ethical discussion is not to theoretically solve the debate between opposing viewpoints, such as between deep 
ecologists and defenders of a strict utilitarianism. The deliberative and critical perspective on earth ethics instead focuses on the way that these and other theoretical positions can have practical significance and evolve under critical social scrutiny. By closely examining the various arguments of a particular form of earth ethics in a given situation, its practical consequences and socially inclusive character, communities and researchers can inform the normative elements of the economic analysis and data gathering process. This, in turn, increases the likelihood that the research outcomes will contribute to guiding sustainability transitions in a legitimate and efficient way.

The second argument in favour of mono-disciplinary and expert-led economic research into sustainability issues is based on the explanatory power of decomposing complex systems into more elementary analytical units, such as utilities and prices. Advocates of the monodisciplinary view uphold the possibility and usefulness of making such a reduction, even though they recognize that this results in introducing a set of approximations and far-reaching abstractions from the real economy (Rosenberg, 1975). However, the latter are regarded as auxiliary hypotheses that accompany the scientific process of building law-like mathematical relationships and not as a fundamental objection to the decomposition of the complex systems into more simple quantifiable parts. This view contrasts with the understanding that, in the case of coupled socio-ecological systems, the phenomena emerge from recurring patterns of interactions between various economic and noneconomic factors, which cannot be studied in isolation from each other independently of the history of these interactions and the particular context.

As we argued in section 2.2 above, the presumption that scholars can generate simple, general predictive models of coupled socio-ecological systems by decomposing these systems into components that can be studied by one discipline has led to a track record of repeated and often dramatic failures in policy advice. Conversely, the alternative approach of "partially decomposable systems" and the use of "typological theories" have proved to be more productive.

Partially decomposable systems are "systems of systems", where each level emerges from the interaction of a specific set of systems at the level below (Ostrom, 2007; Simon, 2000, p. 753), such as socio-ecological systems composed of economic, social and physical sub-systems. The shift in emphasis is therefore a shift away from reducing a system to isolated sub-systems that can be studied through a common metric (whether it be economic, social or biophysical), towards studying the phenomena that result from the interaction of these sub-systems. This leads to the 
need to combine various methodologies and the use of concepts from various disciplines.

Typological theories make it possible to build general theories and causal applications that are valid for a subset of sufficiently similar systems, identified by a set of phenomena that emerge from the interaction between their sub-systems in specific historical circumstances. As indicated in section 2.2, typological theories, which are not universal theories but context-specific for a set of socio-ecological systems, are often presented in the form of integrated frameworks of analysis (Ostrom, 2007). Wellknown examples of such typological theories that have proved extremely productive are the theory of common pool resources developed by Elinor Ostrom (1990) and Fritz Scharpf's analysis of network modes of organization in modern economies (Scharpf, 1997).

Prominent economists such as Alfred Marshall, John Maynard Keynes and, more recently, Richard Nelson, among others, have embraced this complexity-oriented vision of science, based on non-reductionist analysis and typological theory building. For instance, Alfred Marshall, one of the founding fathers of neoclassical economics, definitely did not reject the use of mathematics and mechanistic thinking within economics, but advocated the use of mathematics and mechanistic tools for explaining causal patterns in some sub-systems in a broader empirical, historical and discursive context (Hodgson, 2012, p. xvii). In his opinion, it is this broader interdisciplinary economic theorizing that provides the context for the gathering of empirical facts and the use of mathematical tools: mathematics can clarify mechanisms in sub-systems but is clearly not a substitute for theory building on the complex systems' behaviour itself. This distinction between general integrated frameworks or typological theories of complex systems on the one hand and the analysis of mechanisms in the sub-systems on the other also echoes the distinction made by Nelson and Winter (1982, p. 45; quoted in Hodgson, 2012, p. xxii) between formal and appreciative theory. The broad process of analysis and understanding, with a focus on the endeavour in which the theoretical tools are applied, amounts to appreciative theory, such as in the building of typological theories. By contrast, with formal theory, the focus is on improving and testing the theoretical tools themselves. For Nelson and Winter, these two different kinds of theorizing need to be combined to attain progress in economic understanding.

One consequence of the complexity-oriented vision for sustainability research, more specifically, is the need to adopt a broad interdisciplinary approach to economic analysis. In particular, such an approach implies analysing the interactions between various problem features, for example socio-psychological, political, economic and ecological, depending on their relevance to the economic problems to be analysed, instead of attempting 
to reduce each of these features to some common economic fundamental only. One example of such a reductionist approach is contingent valuation, which uses prices as a metric for revealing individual preferences. Even though this approach has proved useful for revealing established market-related preferences, researchers have shown serious difficulties with the application of these methodologies to environmental values or socio-psychological motivations (Spash, 2000). In spite of this, contingent valuation is still used in much sustainability research. In contrast, an interdisciplinary approach might rely on a combination of various qualitative and quantitative methods. Economic and socio-psychological aspects can, for instance, reliably be studied using well-established quantitative and statistical survey methodologies - mathematical modelling and statistical survey methods, respectively - while political and social aspects might be based on large-scale comparative qualitative research.

A complex system perspective will therefore require the adoption of a multi-method approach for conducting empirical analysis (see also Poteete et al., 2010). The promotion of such an approach by sustainability scholars sharply contrasts with the status acquired by econometric methods as the dominant approach to empirical studies in economics. Indeed, econometrics has been found to be a highly productive method for studying clearly quantifiable phenomena in a methodologically sound manner. At the same time, and partly for this reason, econometrics has also proved to be very attractive to many researchers who are looking for a systematic and well-recognized method of empirical enquiry (Hodgson, 2012, p. xx). Nevertheless, as highlighted throughout this section, analysing complex and multilayered sets of variables through a common metric of study, as is needed for econometric analysis, is neither necessary for conducting sustainability science research, nor likely to be the most appropriate way forward.

Finally, the third argument advocated by champions of the monodisciplinary, value-free, expert-led approach to sustainability economics is related to the priority to be given to formal mathematical tools as the highest standard of rigour both in data analysis and in theory building, even if there is agreement on the need to combine various social science and biophysical disciplinary perspectives. Advocates of the use of the classic toolbox of analytical mathematical tools often refer to the highly successful epistemology of the biophysical sciences, particularly on the assumption that using similar tools as in the biophysical sciences will increase the predictive power of the theories (Rosenberg, 1975). However, even though this view is still at the heart of much neoclassical economic theorizing, at least since the powerful syntheses of Walras and Samuelson (see Boulding, 1948), a growing number of contemporary economists, 
including Nobel Prizewinners like Douglas North (2010) and Herbert Simon, criticize the overly strong emphasis on conventional mathematical formal deductive methodologies as being inadequate for understanding the complexity of modern economies. A fortiori, such a unilateral emphasis is inadequate for studying the kind of complex coupled socio-ecological systems that are the object of sustainability science.

One of the core problems associated with the use of mathematics in social sciences such as economics is related to the openness of the social systems and, in particular, the occurrence of unique novel events (North, 2010, p. 21). The application of formal deductive logical reasoning to physical reality is, in fact, made possible under certain conditions. The most important of these is the experimental control of variables in systems that can be approximately regarded as being closed, that is that can be sufficiently isolated from outside influences, and where the agents within the system behave in a consistent manner (Chick and Dow, 2001, p. 706). Consistency of behaviour, in particular, is a core condition for the formulation of mathematical regularities. This condition can be formulated more specifically as a condition of ergodic behaviour of the variables in closed systems, which means that at least some states of the system will recur in the future - whether in a probabilistic or exact way (North, 2010, p. 19). Under such circumstances, "averages calculated from past observations cannot be persistently different from the time average of future outcomes" (ibid.).

Prominent mathematical economists such as Samuelson considered the ergodic hypothesis to be essential for building scientific economics. However, in the case of social systems, such a hypothesis clearly does not apply. Indeed, the social sciences deal with intrinsically open, uncertain and path-dependent systems. Closed systems, when they occur, are limited in time and space. For instance, throughout history, evolving technologies have produced societal changes that were not and could not have been predicted and that are true novelties creating non-recurring events. Similarly, new socio-economic institutions that contribute to the integration of the world economy, such as the advent of marine insurance (North, 2010), have enabled uncertainties associated with the physical environment to be reduced, but have produced, in turn, a whole new set of uncertainties related to a new world of increased interdependencies and global externalities. To reduce uncertainty in such a world with true novelty, human actors elaborate rational and non-rational beliefs, which, in turn, might successfully or unsuccessfully reduce uncertainty, in particular by making better coordination possible among actors with shared beliefs. A case in point is the role of actors' expectations in elementary macroeconomic models (Chick and Dow, 2001, p. 398). In the absence of perfect information on 
future prices, short-term expectations, together with wages and other costs, determine factory output. Long-term expectations, along with liquidity preferences, determine investment. Demand later determines prices and profits. However, expectations can be mistaken and these beliefs can be later revised, based on new evidence and coordination with other actors. As a result of these revisions, the system evolves into a new state, and so on. One consequence of the role of beliefs in the reduction of uncertainty in socio-economic systems is the need to use a set of interpretative and historical tools in understanding the dynamics of these systems. Such social dynamics of economic beliefs cannot be reduced to mathematical formulas, even in the hypothetical situation of a complete and broad interdisciplinary economic theory that would combine evolutionary theory, neurosciences and neoclassical dynamic stochastic economic theory.

Changes in beliefs are generated by modes of rationality that cannot be reduced to the formal deductive rationality of mathematical reasoning. Consequently, when connecting economic theory to reality, mathematical tools - considered with the contextual and temporal limits discussed in this section - will need to be combined with other tools that can account for the historic and interpretative dimensions of economic expectations. For instance, by collaborating with social and economic actors, researchers can more adequately integrate and critically discuss, in elaborating economic theories, beliefs related to social learning about what a society wants to produce, what natural entitlements society wants to preserve or how society envisions the evolution of social and cultural preferences in relation to issues such as the role of women in the labour market or racial discrimination. Indeed, as also argued by economic philosophers, what is important for understanding economic development is not "learning about the equilibrium entitlements of a set of constraints" imposed prior to the modelling exercise by initially given "supplies of unchanging inputs", but rather incorporating a theory of learning about what a society wants to consume and produce into the modelling process (Gram, 2012, p. 140).

Such a move, beyond expert-driven economic sustainability research towards a socially interactive and deliberative modelling practice, can have rather dramatic consequences for the relationship between theory and practice. In The idea of Justice, Amartya Sen gives a telling example of the difference between top-down, expert-led mathematical advice and the more interactive way of theorizing that integrates rational beliefs about social learning along with contextually situated mathematical modelling (Sen, 2009, pp. 111-13). Within the context of heavily debated population politics during the nineteenth-century demographic boom, two major scientists, Malthus and Condorcet, developed radically different scientific perspectives on demographic evolution. On the one hand, Condorcet preceded 
Malthus in pointing out the possibility of serious global overpopulation based on a set of mathematical population models. However, at the same time, Condorcet was developing nuanced views of this problem, in particular in relation to his work on the promotion of women's education. Condorcet envisioned such education as an important social measure that would generate direct social benefits for families and indirect long-term consequences for social life. On this basis, Condorcet developed a line of mathematical models that showed that social change based on more widespread education could dramatically reduce the population growth rate, and even halt or reverse it. However, Malthus, who built upon the mathematical work of Condorcet, explicitly denied the social and value-related scenarios of Condorcet and rejected, in particular, the role of uncoerced human reasoning by educated citizens in reducing family size (Sen, 2009, p. 112). Accordingly, Malthus developed an alarmist theory of population catastrophe based on the given measurable social and biophysical variables of his time. Unfortunately, Malthus' dire cynicism inspired coercive population politics throughout the world, even though evidence has accumulated ever since on the effects of education in general, and of women in particular, on reducing the growth rate of a population.

The objections to these three lines of argument are especially relevant in the case of sustainability research. For this reason, sustainability scholars in economics have been led to propose a research practice based on more direct collaboration with social actors and practitioners. In particular, transdisciplinary sustainability research in economics is characterized by a focus on a broader set of ethical values, in addition to the quantifiable use values considered in conventional mono-disciplinary research. Indeed, to address the transition to strong sustainability, non-quantifiable values such as cultural values of ecosystems' services, intergenerational equity and intrinsic preferences of nature should play an equally important role in analysing environmentally sound economic behaviour (see Table 3.2). From a methodological perspective, this requirement has led researchers to combine various methodologies, ranging from monetary and nonmonetary quantitative methods, to large-scale comparative qualitative research and case study methodologies. From an organizational perspective, the integration of the ethical perspective has led to involve sustainability stakeholders in the choices amongst the various scenarios for integrating the planet's finite resources into the scientific research.

Well-established practices of sustainability research, such as ecological economics and multi-criteria accounting, aptly illustrate this new mode of research organization in economics. Increasingly however, other research programmes in economics are also addressing sustainability issues in an interdisciplinary way, such as can be seen in behavioural economics' collaboration 
Table 3.2 Transdisciplinary sustainability research in economics

\begin{tabular}{|c|c|c|}
\hline & $\begin{array}{l}\text { Conventional basic } \\
\text { research or applied } \\
\text { research in economics }\end{array}$ & $\begin{array}{l}\text { Transdisciplinary sustainability } \\
\text { research in economics }\end{array}$ \\
\hline $\begin{array}{l}\text { Commitments } \\
\text { concerning the } \\
\text { planet's finite } \\
\text { resources/carrying } \\
\text { capacity }\end{array}$ & $\begin{array}{l}\text { Focus on direct use } \\
\text { values, non-use values } \\
\text { only considered in a } \\
\text { common metric with } \\
\text { the direct use values }\end{array}$ & $\begin{array}{l}\text { Integration in the research } \\
\text { of non-quantifiable non- } \\
\text { use values (cultural values, } \\
\text { intergenerational equity, } \\
\text { intrinsic preferences) }\end{array}$ \\
\hline $\begin{array}{l}\text { Theoretical approach } \\
\text { of socio-ecological } \\
\text { systems }\end{array}$ & $\begin{array}{l}\text { Mono-disciplinary, } \\
\text { quantitative analysis } \\
\text { of the economic } \\
\text { sub-system }\end{array}$ & $\begin{array}{l}\text { Interdisciplinary research, } \\
\text { multi-method research } \\
\text { combining quantitative and } \\
\text { qualitative methods among } \\
\text { others }\end{array}$ \\
\hline $\begin{array}{l}\text { Practical approach of } \\
\text { the science-society } \\
\text { interface }\end{array}$ & $\begin{array}{l}\text { "Value-neutral" advice } \\
\text { to policy, mono- } \\
\text { disciplinary peer } \\
\text { community }\end{array}$ & $\begin{array}{l}\text { Input of sustainability } \\
\text { stakeholders in the research } \\
\text { process; extended peer review; } \\
\text { organization of a process for } \\
\text { reconciling/combining various } \\
\text { values and perspectives on } \\
\text { problem framing }\end{array}$ \\
\hline
\end{tabular}

with environmental psychology and sociology (Reeson, 2008; Videras et al., 2012; Cardenas and Stranlund, 2000) or in the Veblenian evolutionary economics and post-Keynesian macroeconomics discussed above.

Three final comments are appropriate in order to qualify this analysis of existing transformative science approaches for sustainability. First, although the analysis in this book mainly focuses on economics, environmental sciences and science, society and technology studies, the need to combine interdisciplinarity with an ethical framework of strong sustainability and a transdisciplinary organization of the research process is a more general feature of sustainability science. These conditions also apply to other disciplines within sustainability research, such as political science (Ostrom, 2007), psychology (Earl, 2005) and history (Costanza et al., 2012) amongst others. Indeed, these specific conditions are related to the nature of the sustainability problems at hand, characterized by features of strong uncertainty, coupled complex system dynamics and entanglement of facts and values as highlighted throughout Chapters 2 and 3.

Second, as shown by our analysis, the innovative approaches within sustainability science integrate the three core dimensions of sustainability research with various degrees of strength. For example, in post-Keynesian 
Table 3.3 Progressive implementation of the three dimensions of sustainability research in the transformative science approaches analysed in this book

Sustainability Inter-disciplinarity Trans-disciplinarity ethics

\begin{tabular}{|c|c|c|c|}
\hline \multicolumn{4}{|c|}{ Sustainability science approaches analysed in this book } \\
\hline Ecological economics & ++ & ++ & ++ \\
\hline $\begin{array}{l}\text { Multi-criteria } \\
\text { accounting }\end{array}$ & ++ & ++ & ++ \\
\hline $\begin{array}{l}\text { Post-Keynesian } \\
\text { macroeconomics }\end{array}$ & + & +++ & ++ \\
\hline $\begin{array}{l}\text { Veblenian } \\
\text { evolutionary } \\
\text { economics }\end{array}$ & + & +++ & + \\
\hline Earth system science & ++ & +++ & + \\
\hline $\begin{array}{l}\text { Transition approach } \\
\text { to socio- } \\
\text { technological } \\
\text { systems }\end{array}$ & + & ++ & ++ \\
\hline \multicolumn{4}{|c|}{ Other illustrations from the literature } \\
\hline $\begin{array}{l}\text { Political economy of } \\
\text { commons (Ostrom, } \\
\text { 2005; Benkler, 2006; } \\
\text { mainly drawing } \\
\text { upon political } \\
\text { science, ecology and } \\
\text { anthropology) }\end{array}$ & ++ & +++ & + \\
\hline $\begin{array}{l}\text { Environmental } \\
\text { Behavioural } \\
\text { Economics (Richter } \\
\text { and van Soest, 2012; } \\
\text { Frey and Jegen, } \\
\text { 2001; Hudon, 2008; } \\
\text { mainly drawing } \\
\text { upon economics, } \\
\text { environmental } \\
\text { psychology and } \\
\text { sociology) }\end{array}$ & + & +++ & + \\
\hline
\end{tabular}

Notes: $\quad+=$ early stage $;++=$ well developed $;+++=$ fully integrated. 
macroeconomics, the focus is more on the interdisciplinary dimension and the social relevance of economic science than on the ethical framework. Nevertheless, as seen above, recent developments have started to integrate the issue of strong sustainability into the post-Keynesian models. In contrast, earth system science develops an elaborate complex system approach to coupled socio-ecological systems within an ethics of strong sustainability. But earth system science has only recently further developed the requirement of transdisciplinarity, in particular in the latest science plan of the Earth System Science partnerships (Ignaciuk et al., 2012). The variation amongst the sustainability science programmes discussed in this book has been schematically represented in Table 3.3.

Third, sustainability research still faces many institutional barriers. These barriers will be discussed in more detail in the next two chapters. For example, training opportunities for transdisciplinary research are still lacking and interdisciplinarity in funded research projects is hampered by lack of transdisciplinary expertise in research evaluation committees. Therefore, the establishment of sustainability as a fully-fledged research endeavour, on the same footing as, for example, industry-oriented research or non-oriented fundamental research, will require a gradual social learning and institutionalization process. To reach this goal, both exemplary sustainability science programmes that already strongly implement each of the three dimensions of sustainability science and emerging strategic researches for sustainability that integrate the three dimensions to a lesser degree, deserve to be supported. This issue will be more fully explored in the remainder of the book. 